\title{
An Improved Rotor Speed Observer for Standalone Brushless Doubly-Fed Induction Generator under Unbalanced and Nonlinear loads
}

\author{
Yi Liu, Member, IEEE, Wei Xu, Senior Member, IEEE, Teng Long, Member, IEEE, \\ and Frede Blaabjerg, Fellow, IEEE
}

\begin{abstract}
The conventional control methods for brushless doubly-fed induction generator (BDFIG) normally employ mechanical sensors to acquire the information of rotor speed, which brings many disadvantages in the cost, complexity, reliability, and so on. This paper presents an improved rotor speed observer (RSO) for the sensorless operation of standalone BDFIGs, which is based on the power winding (PW) voltage and control winding $(\mathrm{CW})$ current. In order to eliminate the impact of unbalanced and nonlinear loads on the RSO, second-order generalized integrators (SOGIs) and low-pass filters (LPFs) are introduced to pre-filter the $P W$ voltage and $C W$ current, respectively. Through comprehensive parameter design, the response speed of the improved RSO will be not lower than that of the basic RSO with ensuring the filtering effect of these additional filters. In addition, the proposed RSO is independent to machine parameters except the pole pairs. Comprehensive experiments are conducted and results verify the proposed improved RSO applied to the standalone BDFIG. Also, the applicability of the proposed RSO on another dual-electrical-port machine, DFIG, is confirmed by simulation results. ${ }^{1}$
\end{abstract}

Index Terms- Brushless doubly-fed induction generator (BDFIG), standalone power generation system, rotor speed observer (RSO), unbalanced load, nonlinear load.

\section{INTRODUCTION}

The brushless doubly-fed induction generator (BDFIG) is a new type of ac induction machine that contains two separate stator windings, the power winding (PW) and the control winding $(\mathrm{CW})$, which are with different pole pairs. The configuration of BDFIG is illustrated in Fig. 1. Compared with

This work was supported in part by the National Natural Science Foundation of China under Grants 51707079, 51877093 and 51807075; and in part by the National Key Research and Development Program of China under Grant 2018YFE0100200. (Corresponding author: Wei Xu.)

Y. Liu is with the State Key Laboratory of Advanced Electromagnetic Engineering and Technology, School of Electrical and Electronic Engineering, Huazhong University of Science and Technology, Wuhan 430074, China, and also with the School of Electromechanical and Automobile Engineering, Huanggang Normal University, Huanggang 438000, China (e-mail: liuyi82@hust.edu.cn).

W. $\mathrm{Xu}$ is with the State Key Laboratory of Advanced Electromagnetic Engineering and Technology, School of Electrical and Electronic Engineering, Huazhong University of Science and Technology, Wuhan 430074, China (email:weixu@hust.edu.cn).

T. Long is with the Department of Engineering, University of Cambridge, Cambridge, United Kingdom (e-mail: t1322@cam.ac.uk).

F. Blaabjerg is with the Department of Energy Technology, Aalborg University, Aalborg DK-9220, Denmark (e-mail: fbl@et.aau.dk). the doubly-fed induction generator (DFIG), the BDFIG, without electric brushes and slip rings, has the merits of longer work life, higher reliability and lower maintenance cost [1].

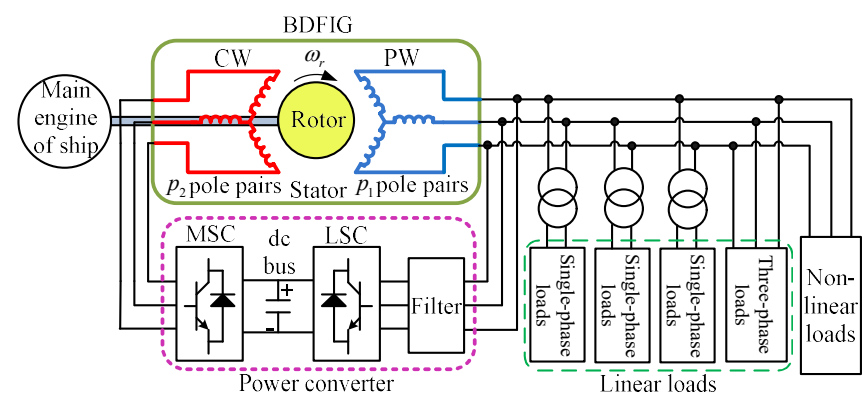

Fig. 1. Structure of the standalone BDFIG system for ship shaft power generation applications, where PW stands for power winding, CW for control winding, MSC for machine side converter, and LSC for line side converter.

Recently, the standalone BDFIG has exhibited excellent energy saving performance in variable speed constant frequency ship shaft power generation systems [2]. The structure of the standalone BDFIG system for ship shaft power generation applications is shown in Fig. 1, where the machine side converter (MSC) is employed to feed the variable frequency exciting current to the $\mathrm{CW}$, and the line side converter (LSC) sharing the same dc bus as the MSC is connected to the PW to regulate the dc bus voltage and to achieve the bidirectional power flow.

The stator-flux-oriented vector control schemes for gridconnected BDFIG wind generators have been studied under balanced and unbalanced operations [3] and [4], in which the rotor speed is a key feedback quantity and measured by a mechanical speed sensor. The steady-state performance of the standalone BDFIG system has been investigated in [5]. The standalone ship shaft power generator system based on the BDFIG with a wound rotor has been developed and applied to the power station of a container vessel [6]. In this system, the voltage amplitude and frequency of PW are kept constant under variable rotor speeds and loads by utilizing a current vector controller to regulate the $\mathrm{CW}$ current. The $\mathrm{CW}$ current vector angle, a key input of the current vector controller, is derived from the rotor speed measured by a shaft encoder. A vector control strategy of BDFIG has been presented in [7] for standalone power generation applications, which is based on the PW flux orientation and with a transient feedforward compensation for CW current. In this control scheme, the rotor position needs to be measured by an encoder, since it involves 
in calculating the reference angle of the frame transformation for the PW flux. In [8], a decoupling network method for inner current loops of standalone BDFIG systems has been designed without using the rotor position information. However, the rotor position is still involved in the outer voltage loop, and the proposed decoupling network method for inner current loops could not work properly under unbalanced load conditions. Besides, many other BDFIG research works almost exclusively rely on the rotor position or speed sensor for closed-loop control, such as phase-angle control [9], indirect stator-quantities control [10], direct torque control [11], generalized vector control [12], and fault ride-through control [13].

Nevertheless, the sensorless operation is desirable as shaft speed sensors bring many drawbacks, such as increasing the system cost and complexity, decreasing the reliability and installation flexibility, and so on. Therefore, in order to address these issues, it is desired to dynamically observe the rotor speed without mechanical speed sensors. Some other papers have discussed the rotor speed observers (RSOs) for the brushless doubly-fed reluctance generator (BDFRG), which is similar to the BDFIG [14], [15]. It is noted that the RSOs proposed in both [14] and [15] need a few specific machine parameters (i.e. the PW inductance and PW resistance) to estimate the PW flux. However, in a standalone BDFIG system of a ship, unbalanced and nonlinear loads are frequently connected to the system, leading to distortion of PW voltage and current. Hence, the PW flux is difficult to observe accurately, and consequently the estimated rotor speed is not accurate by this way. Moreover, the dependence on machine parameters will also reduce the robustness of the flux-estimation based RSO.

In general, as shown in Fig. 1, the electrical loads of a standalone power generation system include linear three-phase loads, linear single-phase loads and nonlinear loads. If unbalanced faults occur in three-phase loads, or the loads on the three single-phase power lines are unequal, the total threephase load is unbalanced. The unbalanced load causes the unbalanced three-phase PW current, which results in the unbalanced three-phase PW terminal voltage. Under nonlinear loads, the PW current contains significant harmonics, especially the $5^{\text {th }}$ and $7^{\text {th }}$ harmonics, which generates the distorted PW terminal voltage. Moreover, due to indirect coupling between $\mathrm{PW}$ and $\mathrm{CW}$ through the rotor, the $\mathrm{CW}$ current also contains abundant harmonics induced by the unbalanced/distorted PW current.

In order to compensate the unbalanced/distorted PW terminal voltage, the function of the active power filter can be integrated to the LSC. This method has been applied to the standalone DFIG system as described in [16]. Also, utilizing the MSC, a few harmonics can be actively injected into the DFIG and BDFIG to compensate for the unbalance and distortion of the two generators' output voltage as shown in [16] and [17]. It can be noted that, with the compensation from the MSC, the transfer function of the compensation control loop for the BDFIG is more complicated than that for the DFIG, which may lead to poorer dynamic performance.
Maybe, the compensation strategy of the MSC needs to be further improved for applying to BDFIG. Furthermore, the joint control of the MSC and LSC proposed in [18] can combine the capabilities of the two converters to compensate the PW terminal voltage so as to extend the operating range the standalone BDFIG under unbalanced and nonlinear loads. To determine the best compensation method among the three ones mentioned above, comparative research and discussion should be implemented in the future.

In [19], a basic RSO based on PW voltage and CW current (the necessary sampled feedback quantities for the standalone BDFIG control system) has been developed for sensorless control of the standalone BDFIG. According to [18], if the LSC is utilized to compensate the unbalanced/distorted PW terminal voltage, the CW current would not be distorted, so that the basic RSO proposed in [19] can estimate the rotor speed well. However, with the compensation only from the MSC or from the combination of MSC and LSC, some harmonics will be actively injected into the CW current [17], [18], which results that the basic RSO cannot run well. In addition, under unbalanced and nonlinear loads, even though a compensation method is applied to the standalone BDFIG, a transient process would inevitably occur, during which both the PW voltage and CW current may be distorted. In this case, the basic RSO also cannot obtain the accurate rotor speed required for the MSC control. Hence, it is necessary to improve the basic RSO to accurately observe the rotor speed for the standalone BDFIG feeding unbalanced and nonlinear loads. For this purpose, an improved RSO has also been presented in [19]. However, the impact of unbalanced and nonlinear loads on the RSO has not been analyzed, and the parameter design has not been developed. In [20], a similar improved RSO has been applied to sensorless control of the standalone BDFIG with unbalanced loads, but it has not been verified under nonlinear loads.

Compared to the work previously presented in [19], in this paper, the analysis of the impact of unbalanced and nonlinear loads on the RSO is performed, a comprehensive guideline for parameter tuning of the improved RSO is developed to ensure a similar dynamic performance with the basic RSO under different loads, and more comprehensive experimental results are presented. Besides, the applicability of the improved RSO on another dual-electrical-port machine, i.e. DFIG, is confirmed by simulation results. Such observer can be used under unbalanced and nonlinear loads and independent to any electrical parameters of the generator although it requires the knowledge of the pole pairs.

\section{PRINCIPLE AND PERFormance ANALysis of BASIC Rotor SPEED OBSERVER}

\section{A. Working Principle}

The BDFIG can operate in several modes, i.e. synchronous, cascade and induction modes [1]. The synchronous mode, also called the doubly-fed mode, is the optimal one. Under this mode, the mechanical rotor speed of BDFIG can be decided by 


$$
\left(p_{1}+p_{2}\right) \omega_{r}=\omega_{1}+\omega_{2}
$$

where $p$ is the number of pole pairs, $\omega$ the angular frequency, and the subscripts 1,2 , and $r$ indicate the $\mathrm{PW}, \mathrm{CW}$, and rotor, respectively.

When the $\mathrm{CW}$ frequency $\omega_{2}$ is set to zero, the natural synchronous speed of the BDFIG can be obtained, above which the rotor speed is called the super-synchronous speed, and below which that is the sub-synchronous speed. When the rotor speed varies, in order to keep the PW frequency $\omega_{1}$ constant, the value of $\omega_{2}$ should be changed by

$$
\omega_{2}=-\omega_{1}+\omega_{r}\left(p_{1}+p_{2}\right) \text {. }
$$

The basic RSO has been developed in [19], with the structure illustrated in Fig. 2, where $u_{1 \alpha}$ and $u_{1 \beta}$ are the $\alpha$ - and $\beta$-components of the PW voltage, $i_{2 \alpha}$ and $i_{2 \beta}$ are those of the $\mathrm{CW}$ current, $\theta_{1}$ and $\theta_{2}$ are the phase angles of the PW voltage and $\mathrm{CW}$ current, respectively, and $\theta_{r v}$ is the virtual rotor position serving as an intermediate variable for deriving the rotor speed.

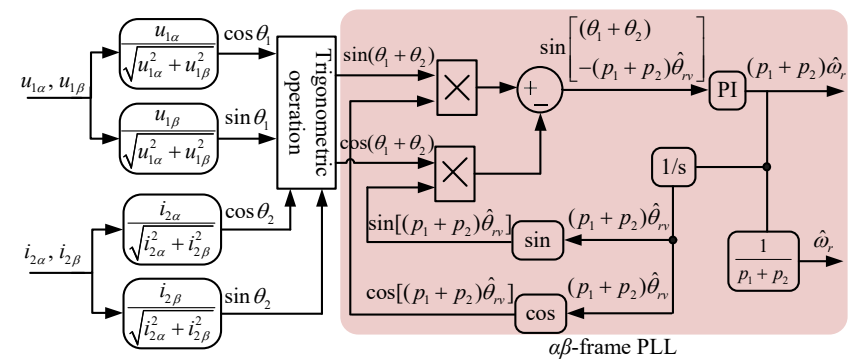

Fig. 2. Structure of the basic RSO [19].

As can be seen from Fig. 2, the basic RSO employs the PW voltage and $\mathrm{CW}$ current to estimate the rotor speed. The values of $\sin \left(\theta_{1}+\theta_{2}\right)$ and $\cos \left(\theta_{1}+\theta_{2}\right)$ are calculated by trigonometric operation and then input to the $\alpha \beta$-frame PLL [21]. If integrating both sides of (1) and ignoring the integration constant, the following expression can be obtained:

$$
\left(p_{1}+p_{2}\right) \theta_{r v}=\theta_{1}+\theta_{2} \text {. }
$$

When the $\alpha \beta$-frame PLL is working in the quasi-locked state, based on (3), the difference between the actual and estimated virtual rotor positions, $\Delta \theta_{r v}$, can be expressed as

$$
\begin{aligned}
\left(p_{1}+p_{2}\right) \Delta \theta_{r v} & =\left(p_{1}+p_{2}\right)\left(\theta_{r v}-\hat{\theta}_{r v}\right) \\
& =\left(\theta_{1}+\theta_{2}\right)-\left(p_{1}+p_{2}\right) \hat{\theta}_{r v} \\
& \approx \sin \left[\left(\theta_{1}+\theta_{2}\right)-\left(p_{1}+p_{2}\right) \hat{\theta}_{r v}\right]
\end{aligned}
$$

The $\Delta \theta_{r v}$ can be regulated to zero by using a PI controller, and consequently the rotor speed can be accurately estimated. The tuning formula for the PI controller parameters of the basic RSO has been derived in [19], which can be expressed as

$$
k_{p_{-} B R S O}=8 / t_{s_{-} B R S O}, k_{i_{-} B R S O}=16 /\left(\xi_{B R S O} t_{s_{-} B R S O}\right)^{2}
$$

where $k_{p_{-} B R S O}$ and $k_{i_{-} B R S O}$ are the proportional gain and integral gain, $t_{S_{B} B R S O}$ and $\xi_{B R S O}$ are the settling time and damping factor, respectively.

\section{B. Performance Analysis under Unbalanced and Nonlinear Loads}

Unbalanced loads and nonlinear loads can generate unbalanced and distorted PW terminal voltages, respectively, which further produce distorted $\mathrm{CW}$ current through the indirect coupling of the rotor. With the basic RSO, the unbalanced/distorted PW voltage and distorted CW current can cause inaccurate rotor speed observation, the reason of which is fully analyzed as follows.

\section{1) Analysis under Unbalanced Loads}

According to the instantaneous symmetrical component method, the unbalanced three-phase voltage can be decomposed to balanced positive-, negative- and zerosequence components. In a low voltage power generation system used in ships, the three-phase three-wire mode is typically adopted, in which the path for the zero-sequence current component is absent. Hence, no steady state zero sequence component of the PW exists and only positive- and negative-sequence components are considered in this paper.

From (2), the angular frequency of the $\mathrm{CW}$ harmonic current induced by the negative-sequence PW current can be expressed by

$$
\omega_{2}^{-1}=-\omega_{1}^{-1}+\left(p_{1}+p_{2}\right) \omega_{r}=\omega_{1}+\left(p_{1}+p_{2}\right) \omega_{r}
$$

where $\omega_{1}^{-1}$ and $\omega_{2}^{-1}$ stand for angular frequencies of the PW negative-sequence voltage and the corresponding $\mathrm{CW}$ harmonic current, respectively.

Similarly, the angular frequency of the positive-sequence $\mathrm{CW}$ current (i.e. $\mathrm{CW}$ fundamental current) can be expressed as

$$
\omega_{2}^{+1}=-\omega_{1}^{+1}+\left(p_{1}+p_{2}\right) \omega_{r}=-\omega_{1}+\left(p_{1}+p_{2}\right) \omega_{r}
$$

where $\omega_{1}^{+1}$ and $\omega_{2}^{+1}$ are angular frequencies of PW positivesequence voltage and $\mathrm{CW}$ fundamental current, respectively.

Under the constant rotor speed and PW frequency, the angular positions of positive- and negative-sequence PW voltage vectors and those of fundamental and harmonic CW current vectors can be given by

$$
\begin{aligned}
& \left\{\begin{array}{l}
\theta_{1}^{+1}=\int \omega_{1}^{+1} d t=\omega_{1} t+\varphi_{1}^{+1} \\
\theta_{2}^{+1}=\int \omega_{2}^{+1} d t=-\omega_{1} t+\left(p_{1}+p_{2}\right) \omega_{r} t+\varphi_{2}^{+1}
\end{array}\right. \\
& \left\{\begin{array}{l}
\theta_{1}^{-1}=\int \omega_{1}^{-1} d t=-\omega_{1} t+\varphi_{1}^{-1} \\
\theta_{2}^{-1}=\int \omega_{2}^{-1} d t=\omega_{1} t+\left(p_{1}+p_{2}\right) \omega_{r} t+\varphi_{2}^{-1}
\end{array}\right.
\end{aligned}
$$

where $\theta$ is the real angular position, and $\varphi$ the initial angular position.

It is assumed that the amplitudes of positive- and negativesequence PW voltage vectors are $U_{1}^{+1}$ and $U_{1}^{-1}$, and those of fundamental and harmonic $\mathrm{CW}$ current vectors are $I_{2}^{+1}$ and $I_{2}^{-1}$, respectively. Applying trigonometric operations, the angular positions of the real PW voltage and $\mathrm{CW}$ current vectors can be derived as

$$
\left\{\begin{array}{l}
\sin \theta_{1}=K_{1} \sin \theta_{1}^{+1}+K_{2} \sin \theta_{1}^{-1} \\
\cos \theta_{1}=K_{1} \cos \theta_{1}^{+1}+K_{2} \cos \theta_{1}^{-1} \\
\sin \theta_{2}=K_{3} \sin \theta_{2}^{+1}+K_{4} \sin \theta_{2}^{-1} \\
\cos \theta_{2}=K_{3} \cos \theta_{2}^{+1}+K_{4} \cos \theta_{2}^{-1}
\end{array}\right.
$$

where

$$
K_{1}=U_{1}^{+1} / U_{1}, K_{2}=U_{1}^{-1} / U_{1}, K_{3}=I_{2}^{+1} / I_{2}, K_{4}=I_{2}^{-1} / I_{2},
$$




$$
\begin{aligned}
& U_{1}=\sqrt{\left(U_{1}^{+1}\right)^{2}+\left(U_{1}^{-1}\right)^{2}+2 U_{1}^{+1} U_{1}^{-1} \cos \left(2 \omega_{1} t+\varphi_{1}^{+1}-\varphi_{1}^{-1}\right)}, \\
& I_{2}=\sqrt{\left(I_{2}^{+1}\right)^{2}+\left(I_{2}^{-1}\right)^{2}+2 I_{2}^{+1} I_{2}^{-1} \cos \left(-2 \omega_{1} t+\varphi_{2}^{+1}-\varphi_{2}^{-1}\right)} .
\end{aligned}
$$

Substituting (10) to (4), the difference between the actual and estimated virtual rotor positions, $\Delta \theta_{r v}$, can be expressed as

$$
\begin{aligned}
\left(p_{1}+p_{2}\right) \Delta \theta_{r v} & \approx \sin \left[\left(\theta_{1}+\theta_{2}\right)-\left(p_{1}+p_{2}\right) \hat{\theta}_{r v}\right] \\
& =K_{1} K_{3} \sin \left(A_{r}+\varphi_{1}^{+1}+\varphi_{2}^{+1}\right) \\
& +K_{2} K_{3} \sin \left(-2 \omega_{1} t+A_{r}+\varphi_{1}^{-1}+\varphi_{2}^{+1}\right) \\
& +K_{1} K_{4} \sin \left(2 \omega_{1} t+A_{r}+\varphi_{1}^{+1}+\varphi_{2}^{-1}\right) \\
& +K_{2} K_{4} \sin \left(A_{r}+\varphi_{1}^{-1}+\varphi_{2}^{-1}\right)
\end{aligned}
$$

where $A_{r}=\left(p_{1}+p_{2}\right) \omega_{r} t-\left(p_{1}+p_{2}\right) \hat{\theta}_{r v}$, and all the coefficients $K_{1} K_{3}, K_{2} K_{3}, K_{1} K_{4}$, and $K_{2} K_{4}$ contain ac components at the frequency of $2 \omega_{1}$. The detailed derivation process for (11) can be found in Appendix.

The first and last terms in the right side of (11) can be eliminated by adjusting $\hat{\theta}_{r v}$ to make $\left(A_{r}+\varphi_{1}^{+1}+\varphi_{2}^{+1}\right)$ and $\left(A_{r}+\varphi_{1}^{-1}+\varphi_{2}^{-1}\right)$ to zero. However, the other two terms in the right side of (11) both have ac components with the frequency of $2 \omega_{1}$, which cannot be removed, because $2 \omega_{1} t$ and $-2 \omega_{1} t$ cannot be canceled by adjusting $\hat{\theta}_{r v}$. The input of the PI controller of the basic RSO contains ac components at the frequency of $2 \omega_{1}$, which results in fluctuation of the estimated rotor speed at the frequency of $2 \omega_{1}$.

\section{2) Analysis under Nonlinear Loads}

Under nonlinear loads, the most significant harmonics of the PW voltage are the $5^{\text {th }}$ and $7^{\text {th }}$ harmonics with frequencies of $-5 \omega_{1}$ and $7 \omega_{1}$. The corresponding $\mathrm{CW}$ harmonic currents can be generated by the harmonic components of PW current via the indirect coupling of the rotor, whose angular frequencies can be obtained by

$$
\begin{gathered}
\omega_{2}^{-5}=-\omega_{1}^{-5}+\left(p_{1}+p_{2}\right) \omega_{r}=5 \omega_{1}+\left(p_{1}+p_{2}\right) \omega_{r} \\
\omega_{2}^{+7}=-\omega_{1}^{+7}+\left(p_{1}+p_{2}\right) \omega_{r}=-7 \omega_{1}+\left(p_{1}+p_{2}\right) \omega_{r}
\end{gathered}
$$

where $\omega_{1}^{-5}$ and $\omega_{1}^{+7}$ are angular frequencies of the $5^{\text {th }}$ and $7^{\text {th }}$ PW harmonic voltages, and $\omega_{2}^{-5}$ and $\omega_{2}^{+7}$ those of the corresponding $\mathrm{CW}$ harmonic currents induced by the $\mathrm{PW}$ harmonic currents, respectively.

Similarly, under the constant rotor speed and PW fundamental frequency, the angular positions of the $5^{\text {th }}$ and $7^{\text {th }}$ PW harmonic voltage vectors and those of the corresponding harmonic $\mathrm{CW}$ current vectors can be calculated by

$$
\begin{aligned}
& \left\{\begin{array}{l}
\theta_{1}^{-5}=\int \omega_{1}^{-5} d t=-5 \omega_{1} t+\varphi_{1}^{-5} \\
\theta_{2}^{-5}=\int \omega_{2}^{-5} d t=5 \omega_{1} t+\left(p_{1}+p_{2}\right) \omega_{r} t+\varphi_{2}^{-5}
\end{array}\right. \\
& \left\{\begin{array}{l}
\theta_{1}^{+7}=\int \omega_{1}^{+7} d t=7 \omega_{1} t+\varphi_{1}^{+7} \\
\theta_{2}^{+7}=\int \omega_{2}^{+7} d t=-7 \omega_{1} t+\left(p_{1}+p_{2}\right) \omega_{r} t+\varphi_{2}^{+7}
\end{array} .\right.
\end{aligned}
$$

The amplitudes of the $5^{\text {th }}$ and $7^{\text {th }} \mathrm{PW}$ harmonic voltage vectors are assumed to be $U_{1}^{-5}$ and $U_{1}^{+7}$, and those of the corresponding $\mathrm{CW}$ harmonic current vectors to be $I_{2}^{-5}$ and
$I_{2}^{+7}$, respectively. Combining (8), (14) and (15), the angular positions of the real $\mathrm{PW}$ voltage and $\mathrm{CW}$ current vectors can be obtained by

$$
\left\{\begin{array}{l}
\sin \theta_{1}=K_{1} \sin \theta_{1}^{+1}+K_{2} \sin \theta_{1}^{-5}+K_{3} \sin \theta_{1}^{+7} \\
\cos \theta_{1}=K_{1} \cos \theta_{1}^{+1}+K_{2} \cos \theta_{1}^{-5}+K_{3} \cos \theta_{1}^{+7} \\
\sin \theta_{2}=K_{4} \sin \theta_{2}^{+1}+K_{5} \sin \theta_{2}^{-5}+K_{6} \sin \theta_{2}^{+7} \\
\cos \theta_{2}=K_{4} \cos \theta_{2}^{+1}+K_{5} \cos \theta_{2}^{-5}+K_{6} \cos \theta_{2}^{+7}
\end{array}\right.
$$

where

$$
\begin{aligned}
& K_{1}=U_{1}^{+1} / U_{1}, K_{2}=U_{1}^{-5} / U_{1}, K_{3}=U_{1}^{+7} / U_{1}, K_{4}=I_{2}^{+1} / I_{2}, \\
& K_{5}=I_{2}^{-5} / I_{2}, K_{6}=I_{2}^{+7} / I_{2}, \\
& U_{1}=\sqrt{\begin{array}{l}
\left(U_{1}^{+1}\right)^{2}+\left(U_{1}^{-5}\right)^{2}+\left(U_{1}^{+7}\right)^{2}+2 U_{1}^{+1} U_{1}^{-5} \cos \left(6 \omega_{1} t+\varphi_{1}^{+1}-\varphi_{1}^{-5}\right) \\
+2 U_{1}^{-5} U_{1}^{+7} \cos \left(-12 \omega_{1} t+\varphi_{1}^{-5}-\varphi_{1}^{+7}\right) \\
+2 U_{1}^{+1} U_{1}^{+7} \cos \left(-6 \omega_{1} t+\varphi_{1}^{+1}-\varphi_{1}^{+7}\right)
\end{array}} \\
& I_{2}=\sqrt{\begin{array}{l}
\left(I_{2}^{+1}\right)^{2}+\left(I_{2}^{-5}\right)^{2}+\left(I_{2}^{+7}\right)^{2}+2 I_{2}^{+1} I_{2}^{-5} \cos \left(-6 \omega_{1} t+\varphi_{2}^{+1}-\varphi_{2}^{-5}\right) \\
+2 I_{2}^{-5} I_{2}^{+7} \cos \left(12 \omega_{1} t+\varphi_{2}^{-5}-\varphi_{2}^{+7}\right) \\
+2 I_{2}^{+1} I_{2}^{+7} \cos \left(6 \omega_{1} t+\varphi_{2}^{+1}-\varphi_{2}^{+7}\right)
\end{array}}
\end{aligned}
$$

Substituting (16) to (4), the difference between the actual and estimated virtual rotor positions, $\Delta \theta_{r v}$, can be expressed as

$$
\begin{aligned}
\left(p_{1}+p_{2}\right) \Delta \theta_{r v} & \approx \sin \left[\left(\theta_{1}+\theta_{2}\right)-\left(p_{1}+p_{2}\right) \hat{\theta}_{r v}\right] \\
& =K_{1} K_{4} \sin \left(A_{r}+\varphi_{1}^{+1}+\varphi_{2}^{+1}\right) \\
& +K_{1} K_{5} \sin \left(6 \omega_{1} t+A_{r}+\varphi_{1}^{+1}+\varphi_{2}^{-5}\right) \\
& +K_{1} K_{6} \sin \left(-6 \omega_{1} t+A_{r}+\varphi_{1}^{+1}+\varphi_{2}^{+7}\right) \\
& +K_{2} K_{4} \sin \left(-6 \omega_{1} t+A_{r}+\varphi_{1}^{-5}+\varphi_{2}^{+1}\right) \\
& +K_{2} K_{5} \sin \left(A_{r}+\varphi_{1}^{-5}+\varphi_{2}^{-5}\right) \\
& +K_{2} K_{6} \sin \left(-12 \omega_{1} t+A_{r}+\varphi_{1}^{-5}+\varphi_{2}^{+7}\right) \\
& +K_{3} K_{4} \sin \left(6 \omega_{1} t+A_{r}+\varphi_{1}^{+7}+\varphi_{2}^{+1}\right) \\
& +K_{3} K_{5} \sin \left(12 \omega_{1} t+A_{r}+\varphi_{1}^{+7}+\varphi_{2}^{-5}\right) \\
& +K_{3} K_{6} \sin \left(A_{r}+\varphi_{1}^{+7}+\varphi_{2}^{+7}\right)
\end{aligned}
$$

where $A_{r}=\left(p_{1}+p_{2}\right) \omega_{r} t-\left(p_{1}+p_{2}\right) \hat{\theta}_{r v}$, and all the coefficients $K_{1} K_{4}, K_{1} K_{5}, K_{1} K_{6}, K_{2} K_{4}, K_{2} K_{5}, K_{2} K_{6}, K_{3} K_{4}, K_{3} K_{5}$ and $K_{3} K_{6}$ contain ac components with frequencies of $6 \omega_{1}$ and $12 \omega_{1}$. The detailed derivation for (17) can be found in Appendix.

The first, fifth and ninth terms in the right side of (17) can be eliminated by regulating $\hat{\theta}_{r v}$ to make $\left(A_{r}+\varphi_{1}^{+1}+\varphi_{2}^{+1}\right)$, $\left(A_{r}+\varphi_{1}^{-5}+\varphi_{2}^{-5}\right)$ and $\left(A_{r}+\varphi_{1}^{+7}+\varphi_{2}^{+7}\right)$ to zero. The other six terms in the right side of (17), containing ac components at the frequency of $6 \omega_{1}$ or $12 \omega_{1}$, cannot be cleared, because $\pm 6 \omega_{1} t$ and $\pm 12 \omega_{1} t$ in these terms cannot be mitigated by adjusting $\hat{\theta}_{r v}$. As a result, ac components at frequencies of $6 \omega_{1}$ and $12 \omega_{1}$ are inevitable in the PI controller of the basic RSO, which results in fluctuation of the estimated rotor speed at the same frequencies. 


\section{IEEE POWER ELECTRONICS REGULAR PAPER}

According to the analysis above, the basic RSO is unable to obtain the accurate rotor speed when the unbalanced or nonlinear load occurs.

\section{DESIGN OF IMPROVED ROTOR SPEED OBSERVER}

\section{A. Scheme Design}

In order to overcome the aforementioned problems, secondorder generalized integrators (SOGIs) and low-pass filters (LPFs) are introduced to the RSO to pre-filter the PW voltage and CW current, respectively. The improved RSO is illustrated in Fig. 3.

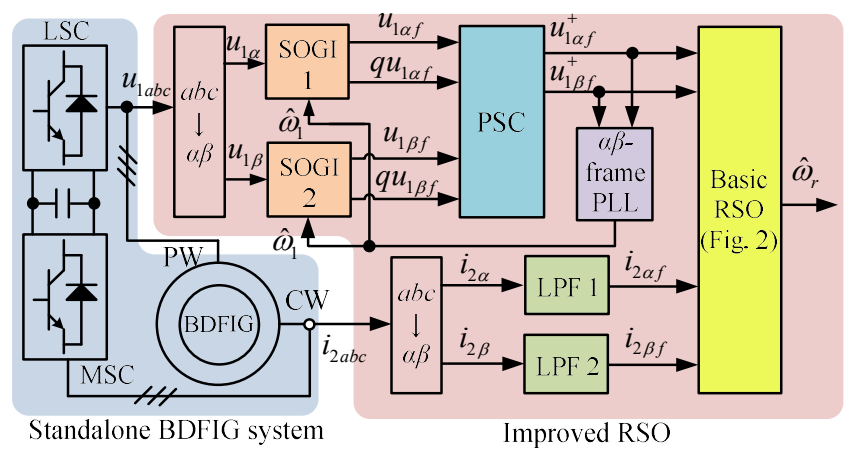

Fig. 3. Overall scheme of the proposed improved RSO, where SOGI stands for second-order generalized integrator, PSC for positive-sequence calculator, LPF for low-pass filter, and RSO for rotor speed observer.

In Fig. 3, two SOGIs are used to extract the fundamental of the $\alpha$ - and $\beta$ - components of PW voltage ( $u_{1 \alpha f}$ and $\left.u_{1 \beta f}\right)$, and to obtain the corresponding 90 -degree phase-shifted results $\left(q u_{1 \alpha f}\right.$ and $\left.q u_{1 \beta f}\right)$ at the same time. The fundamental positivesequence $\alpha$ - and $\beta$ - components of the PW voltage, $u_{1 \alpha f}^{+}$and $u_{1 \beta f}^{+}$, can be derived from the positive-sequence calculator (PSC) according to the following expression [23]:

$$
\left\{\begin{array}{l}
u_{1 \alpha f}^{+}=\left(u_{1 \alpha f}-q u_{1 \beta f}\right) / 2 \\
u_{1 \beta f}^{+}=\left(q u_{1 \alpha f}+u_{1 \beta f}\right) / 2
\end{array} .\right.
$$

And then, both $u_{1 \alpha f}^{+}$and $u_{1 \beta f}^{+}$are sent to the $\alpha \beta$-frame PLL to obtain the estimated PW frequency $\hat{\omega}_{1}$ serving as the resonance frequency of two SOGIs, which makes SOGIs frequency-adaptive.

According to (2), when the BDFIG is across its natural synchronous speed, in order to achieve the constant $\mathrm{PW}$ frequency, the $\mathrm{CW}$ current frequency should be set to zero, which means that the minimum frequency of the $\mathrm{CW}$ fundamental current is zero in actual applications. Hence, two first-order low-pass filters (LPFs) are employed to filter out the harmonics in the $\alpha$ - and $\beta$ - components of the $\mathrm{CW}$ current. Finally, these filtered quantities, $u_{1 \alpha f}^{+}, u_{1 \beta f}^{+}, i_{2 \alpha f}$ and $i_{2 \beta f}$, are all fed to the basic RSO to estimate the rotor speed.

Under unbalanced loads, the negative-sequence PW voltage and the corresponding harmonic $\mathrm{CW}$ current can be filtered out before being sent to the basic RSO, thereafter the coefficients $K_{1}$ and $K_{3}$ in (10) can be approximated as $1, K_{2}$ and $K_{4}$ as 0 . Hence, the ac components with the frequency of $2 \omega_{1}$ in (11) can be eliminated, so that (11) can be simplified as

$$
\left(p_{1}+p_{2}\right) \Delta \theta_{r v} \approx \sin \left(A_{r}+\varphi_{1}^{+1}+\varphi_{2}^{+1}\right) .
$$

As a result, based on (19), $\Delta \theta_{r v}$ can be regulated to zero by using a PI controller, and consequently the accurate rotor speed can be obtained under unbalanced loads. Similarly, (17) can be simplified to the same expression as (19), thus the improved RSO can also accurately estimate the rotor speed under nonlinear loads.

\section{B. Parameter Design}

The performance of the improved RSO depends on so many parameters of all the filters and PI controllers. The comprehensive design of the parameters in all the filters and PI controllers is the key element that the improved RSO is with both good dynamic and good steady-state performance. The idea of the comprehensive parameter design is to make the response speed of the improved RSO not lower than that of the basic RSO with ensuring the filtering effect of these additional filters (i.e. SOGIs and LPFs), which can be implemented in three steps and described as follows.

\section{1) Step 1: Determination of SOGI Parameters}

The transfer functions of the SOGIs in Fig. 3 can be expressed as [23]

$$
\begin{gathered}
\frac{u_{1 \alpha f}(s)}{u_{1 \alpha}(s)}=\frac{u_{1 \beta f}(s)}{u_{1 \beta}(s)}=\frac{2 \xi_{S O G I} \hat{\omega}_{1} s}{s^{2}+2 \xi_{S O G I} \hat{\omega}_{1} s+\hat{\omega}_{1}^{2}} \\
\frac{q u_{1 \alpha f}(s)}{u_{1 \alpha}(s)}=\frac{q u_{1 \beta f}(s)}{u_{1 \beta}(s)}=\frac{2 \xi_{S O G I} \hat{\omega}_{1}^{2}}{s^{2}+2 \xi_{S O G I} \hat{\omega}_{1} s+\hat{\omega}_{1}^{2}}
\end{gathered}
$$

where $\xi_{S O G I}$ is the damping factor, and $\hat{\omega}_{1}$ the resonance frequency (i.e. the estimated PW frequency by the $\alpha \beta$-frame PLL). With consideration of both the response speed and the stability of the SOGI, generally, $\xi_{S O G I}$ is set to 0.707 [23].

From (20) and (21), the settling time of SOGI can be given by

$$
t_{s_{-} S O G I} \approx 4 /\left(\xi_{S O G I} \hat{\omega}_{1}\right) .
$$

If the response speed of the $\alpha \beta$-frame PLL is faster than that of the SOGI, $\hat{\omega}_{1}$ can be regarded as the PW nominal frequency. For the PW nominal frequency of $50 \mathrm{~Hz}$, from (22), it can be derived that $t_{S \text { SOGI }}$ is about $18 \mathrm{~ms}$.

\section{2) Step 2: Determination of PI Controller Parameters}

In order to reduce the impact of the delay of the $\alpha \beta$-frame PLL on the SOGI, the response speed of the $\alpha \beta$-frame PLL has to be faster than that of the SOGI. In addition, the settling times of the SOGI and LPF should be less than that of the basic RSO, so that the response speed of the improved RSO is not slower than that of the basic RSO. Hence, the settling time of different components in the improved RSO should be in the order of

$$
t_{s_{-} P L L}<t_{s_{-} S O G I} \approx t_{s_{-} L P F}<t_{s_{-} B R S O}
$$

where $t_{s_{-} P L L}, t_{s_{-} S O G I}, t_{s_{-} L P F}$, and $t_{s_{-} B R S O}$ are the settling time of the $\alpha \beta$-frame PLL, SOGI, LPF, and basic RSO, respectively. Due to $t_{s_{-} S O G I}$ being about $18 \mathrm{~ms}$, according to (23), it is 


\section{IEEE POWER ELECTRONICS REGULAR PAPER}

appropriate to set $t_{S_{-} P L L}$ and $t_{S_{-} B R S O}$ to $10 \mathrm{~ms}$ and $40 \mathrm{~ms}$, respectively.

Because the basic RSO is derived from the $\alpha \beta$-frame PLL, the linearized control model of the basic RSO is similar to that of the $\alpha \beta$-frame PLL, and consequently the tuning formulas for the PI controller parameters in the two components are the same as shown in (5). Taking into account the tradeoff of response speed and stability, the damping factor in (5) should be set to 0.707 . These PI controller parameters in the $\alpha \beta$-frame PLL and basic RSO can be given by

$$
\begin{aligned}
& k_{p_{-} P L L}=800, k_{i_{-} P L L}=80000 \\
& k_{p_{-} B R S O}=200, k_{i_{-} B R S O}=5000 .
\end{aligned}
$$

\section{3) Step 3: Determination of LPF Parameters}

The cutoff frequency of the first-order LPF needs to be determined. From (6), (7), (12) and (13), the relationship between angular frequencies of $\mathrm{CW}$ fundamental current and harmonic currents can be derived as

$$
\begin{aligned}
& \omega_{2}^{-1}=\omega_{2}^{+1}+2 \omega_{1} \\
& \omega_{2}^{-5}=\omega_{2}^{+1}+6 \omega_{1} \\
& \omega_{2}^{+7}=\omega_{2}^{+1}-6 \omega_{1} .
\end{aligned}
$$

In order to employ a fractionally rated power converter to drive the standalone BDFIG system, the angular frequency of $\mathrm{CW}$ fundamental current, $\omega_{2}^{+1}$, is usually limited to $30 \%$ of the PW frequency (i.e., between $-0.3 \omega_{1}$ and $0.3 \omega_{1}$ ). It is noted that the phase sequence of the $\mathrm{CW}$ current with negative frequency is opposite to that of the $\mathrm{CW}$ current with positive frequency. Thus, the maximum absolute value of the $\mathrm{CW}$ fundamental current frequency, $\left|\omega_{2 f}\right| \max$, is $0.3 \omega_{1}$, and from (26)-(28), the minimum absolute value of $\mathrm{CW}$ harmonic current frequency, $\left|\omega_{2 h}\right|_{\min }$, is $1.7 \omega_{1}$.

The first-order LPF can be expressed as

$$
\operatorname{LPF}(s)=\frac{\omega_{c}}{s+\omega_{c}}
$$

where $\omega_{c}$ is the cutoff frequency.

In order to achieve stronger harmonic attenuation and weaker fundamental decay, the cutoff frequency should be smaller than the minimum absolute value of the $\mathrm{CW}$ harmonic current frequency and greater than the maximum absolute value of $\mathrm{CW}$ fundamental current frequency as much as possible, as shown in Fig. 4, which means that the optimal cutoff frequency $\omega_{c_{-} \text {opt }}$ can be determined by

$$
\lg \frac{\omega_{c_{-} o p t}}{\omega_{c_{-} o p t}}=\frac{1}{2}\left(\lg \frac{\left|\omega_{2 f}\right|_{\max }}{\omega_{c_{-} o p t}}+\lg \frac{\left|\omega_{2 h}\right|_{\min }}{\omega_{c_{-} o p t}}\right) .
$$

From (30), $\omega_{\text {c_opt }}$ can be expressed as

$$
\omega_{c_{-} o p t}=\sqrt{\left|\omega_{2 f}\right|_{\max } *\left|\omega_{2 h}\right|_{\min }} \approx 0.7 \omega_{1} .
$$

Hence, with the PW nominal frequency of $50 \mathrm{~Hz}$, the actual cutoff frequency $\omega_{c}$ should be set to around $2 \pi \times 35 \mathrm{rad} / \mathrm{s}$. According to [24], when the steady-state error is limited to $2 \%$, the settling time of the first-order LPF is given by

$$
t_{s_{-} L P F}=4 / \omega_{c} \approx 18 \mathrm{~ms} \text {. }
$$

Consequently, it is known that the $t_{S_{-} L P F}$ can exactly meet the requirement of (23).

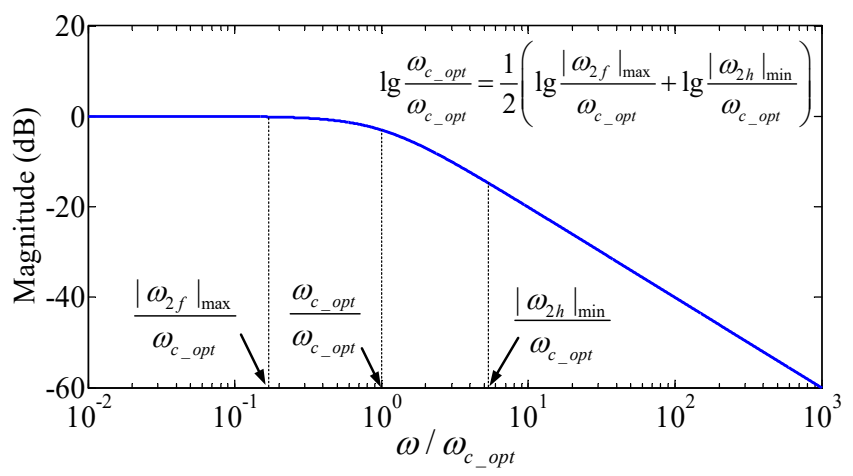

Fig. 4. Magnitude-frequency characteristics of first-order LPF with normalized scale for frequency, where $\omega_{c_{-} \text {opt }}$ is the optimal cutoff frequency, $\left|\omega_{2 f}\right|_{\max }$ the maximum absolute value of $\mathrm{CW}$ fundamental current frequency, and $\left|\omega_{2 h}\right|_{\min }$ the minimum absolute value of $\mathrm{CW}$ harmonic current frequency.

\section{EXPERIMENTAL RESULTS WITH BDFIG}

\section{A. Experimental Setup}

The experiments are performed on a prototype BDFIG, whose main parameters are listed in Table I. A $37 \mathrm{~kW}$ threephase asynchronous motor as the prime mover is mechanically coupled to the BDFIG and driven by a Siemens MM430 inverter, as shown in Fig. 5. The rotor speed is measured by an incremental encoder for validating the performance of the proposed RSO. The control of MSC and LSC employs the conventional methods proposed in [2] and [22], respectively. The nominal rms and frequency of the PW line voltage is 400 $\mathrm{V}$ and $50 \mathrm{~Hz}$, respectively.

TABLE I

MAIN PARAMETERS OF THE PROTOTYPE BDFIG IN EXPERIMENT

\begin{tabular}{ll}
\hline \hline Parameter & Value \\
\hline \hline Capacity & $30 \mathrm{kVA}$ \\
Speed range & $600 \sim 1200 \mathrm{rpm}$ \\
PW and CW pole pairs & 1,3 \\
PW rated voltage and current & $380 \mathrm{~V}, 45 \mathrm{~A}$ \\
$\mathrm{CW}$ voltage and current range & $0 \sim 350 \mathrm{~V}, 0 \sim 50 \mathrm{~A}$ \\
PW, CW, and rotor resistances & $0.4034 \Omega, 0.2680 \Omega, 0.3339 \Omega$ \\
PW, CW, and rotor self-inductances & $0.4749 \mathrm{H}, 0.03216 \mathrm{H}, 0.2252 \mathrm{H}$ \\
Mutual inductance between PW and rotor & $0.3069 \mathrm{H}$ \\
Mutual inductance between CW and rotor & $0.02584 \mathrm{H}$ \\
Rotor type & Wound rotor \\
\hline \hline
\end{tabular}

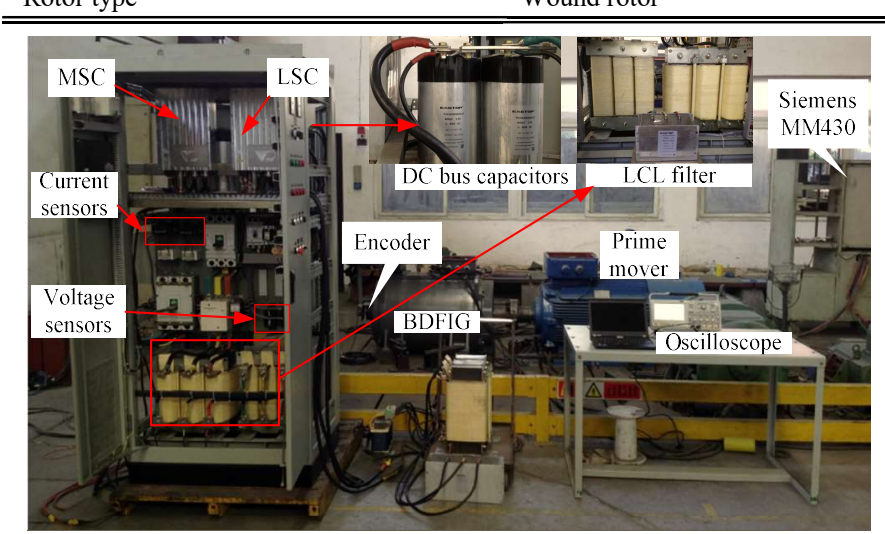

Fig. 5. Photograph of the experimental setup. 


\section{B. Dynamic Performance Test}

Three typical experiments have been carried out under the unbalanced, nonlinear and combination loads, respectively. The controller of the experimental machine still uses the encoder to measure the rotor speed. The basic and improved RSOs are employed to observe the rotor speed separately to compare the performance and validate the capability of the proposed improved RSO in coping with unbalance and distortion of measured variables. According to the description in Part B of Section III, the control parameters and settling time of different components in the improved RSO can be summarized in Table II. For a fair comparison, the same basic RSO control parameters as shown in Table II are utilized when employing only the basic RSO to estimate the rotor speed.

TABLE II

CONTROL PARAMETERS AND SETTLING TIMES OF DifFERENT COMPONENTS IN

\begin{tabular}{ccc}
\multicolumn{3}{c}{ THE IMPROVED RSO } \\
\hline \hline Component & Control parameter & Settling time $(\mathrm{ms})$ \\
\hline \hline SOGI & $\xi_{\text {SOGI }}=0.707$ & 18 \\
LPF & $\omega_{c}=2 \pi 35 \mathrm{rad} / \mathrm{s}$ & 18 \\
$\alpha \beta$-frame PLL & $k_{p_{-} P L L}=800, k_{i-P L L}=80000$ & 10 \\
Basic RSO & $k_{p_{-} B R S O}=200, k_{i-B R S O}=5000$ & 40 \\
\hline \hline
\end{tabular}

1) Experiment under Unbalanced Load

At $0.77 \mathrm{~s}$, the standalone BDFIG is operated to supply an unbalanced three-phase resistive load with resistances of $25 \Omega$, $100 \Omega$, and $100 \Omega$ in phases $a, b$, and $c$. From 4 to $8.2 \mathrm{~s}$, the rotor speed rises from 620 to $939 \mathrm{rpm}$, and falls from 939 to $606 \mathrm{rpm}$ between 10 and $18.8 \mathrm{~s}$. As can be seen from Figs. 6(a) and (b), the unbalanced load makes the PW voltage significantly unbalanced with the unbalance factor (UF) of $14.1 \%$, which further distorts the $\mathrm{CW}$ current. As shown in Figs. 6(c)-(f), the basic RSO and the improved one have similar response speed. In addition, as shown in Fig. 6(d), the peak-to-peak value of the oscillation in the rotor speed error of the basic RSO is about $12 \mathrm{rpm}$, and it can be significantly reduced to around $3 \mathrm{rpm}$ by the improved RSO as shown in Fig. 6(f). Hence, the overall performance of the improved RSO is better than that of the basic RSO under unbalanced loads.

\section{2) Experiment under Nonlinear Load}

The standalone BDFIG is connected with a nonlinear load (a diode-rectifier with a $25 \Omega$ resistor at the dc side) at $2.43 \mathrm{~s}$. Between 4.46 and $17.33 \mathrm{~s}$, the rotor speed rises from 597 to $928 \mathrm{rpm}$ and then falls to $694 \mathrm{rpm}$. As shown in Figs. 7(a) and (b), the nonlinear load results in significant harmonics in the PW voltage with the total harmonic distortions (THD) of 9.1\%, and the $\mathrm{CW}$ current is distorted at the same time. At the time of the non-linear load being connected, a little error in the speed estimation, about $3.1 \%$ of the real speed, appears and then rapidly converges to $0.5 \%$ within $0.28 \mathrm{~s}$ as shown in Figs. $7(d)$ and (f). Comparing the experimental results as shown in Figs. 7(c)-(f), the response speed of the two observers is nearly identical with each other. However, the oscillation in the rotor speed observed by the basic RSO reaches $20 \mathrm{rpm}$, as shown in Fig. 7(d). At the same operation condition, the

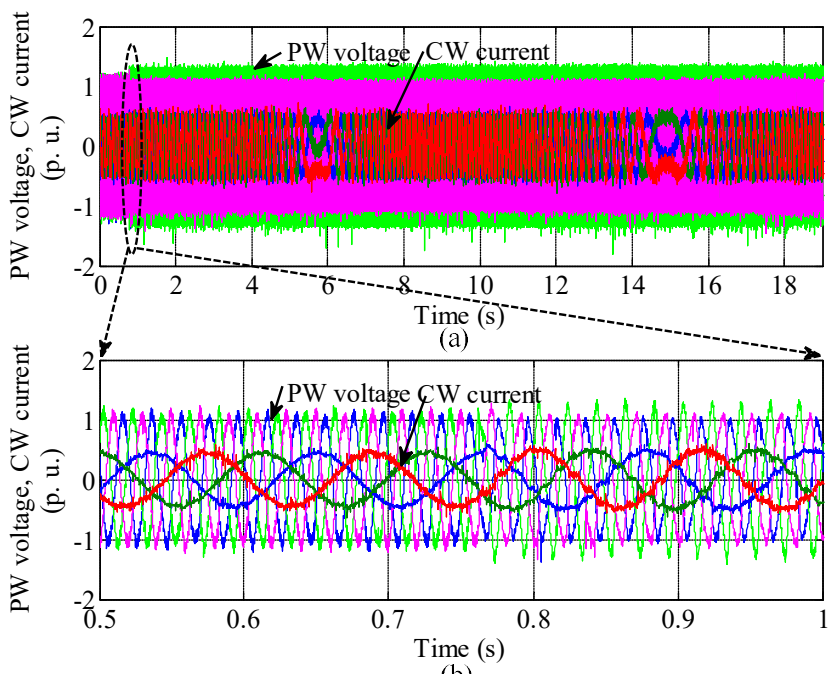

(b)

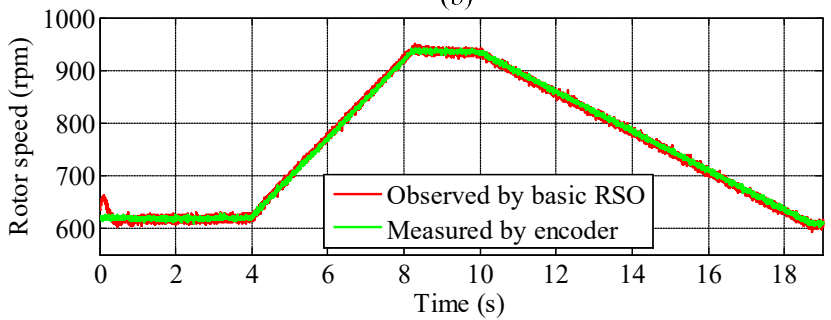

(c)

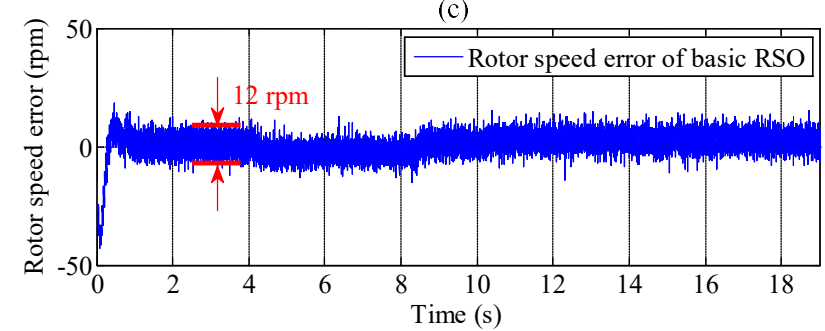

(d)

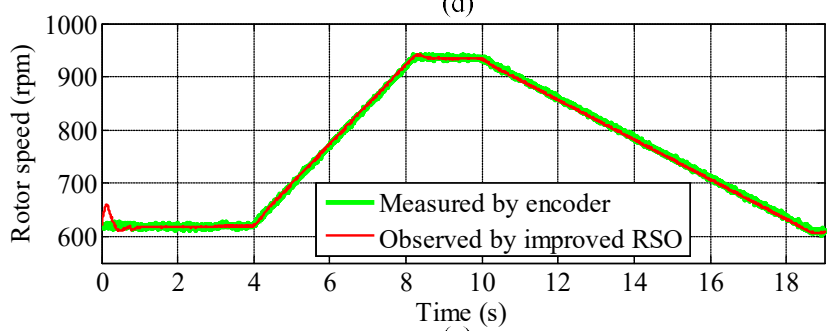

(e)

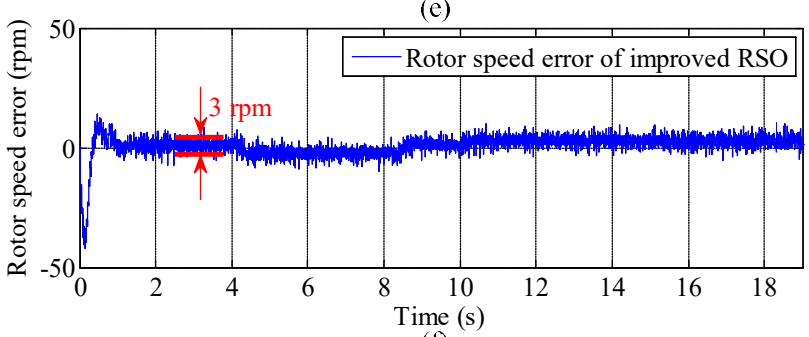

(f)

Fig. 6. Experimental results of the standalone BDFIG supplying an unbalanced three-phase resistive load with resistance of $25 \Omega, 100 \Omega$, and 100 $\Omega$ in phases $a, b$, and $c$, where (a) PW voltage ( 1 p. u. $=500 \mathrm{~V})$ and CW current ( 1 p. u. $=50$ A), (b) Expanded view of (a), (c) Rotor speeds observed by basic RSO and measured by encoder, (d) Error of the rotor speed observed by basic RSO, (e) Rotor speeds observed by improved RSO and measured by encoder, and (f) Error of the rotor speed observed by improved RSO. 


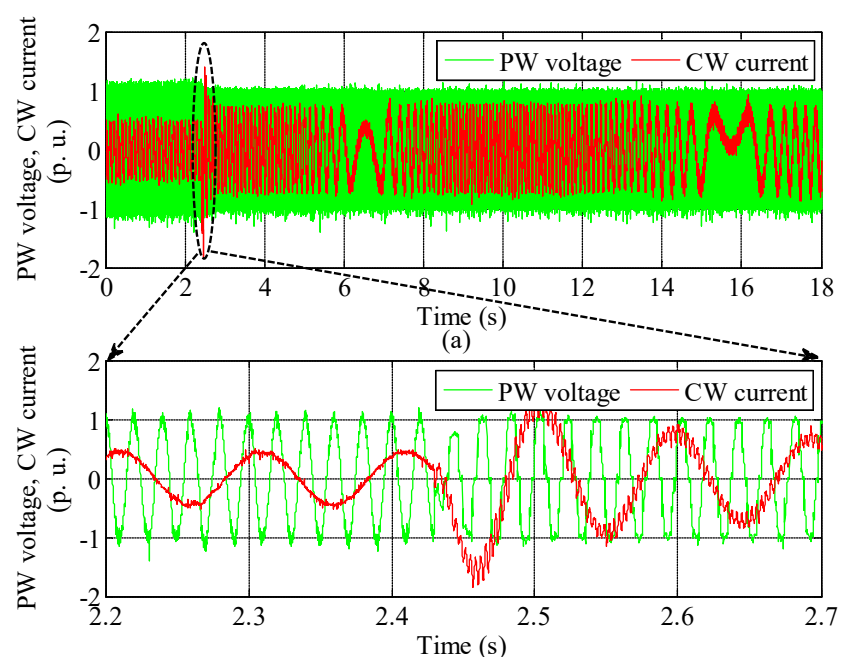

(b)

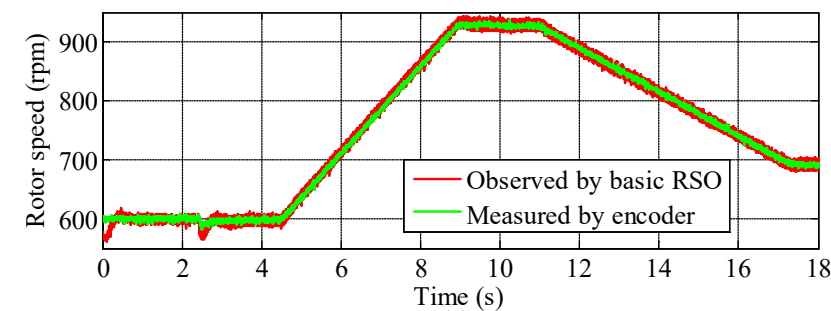

(c)

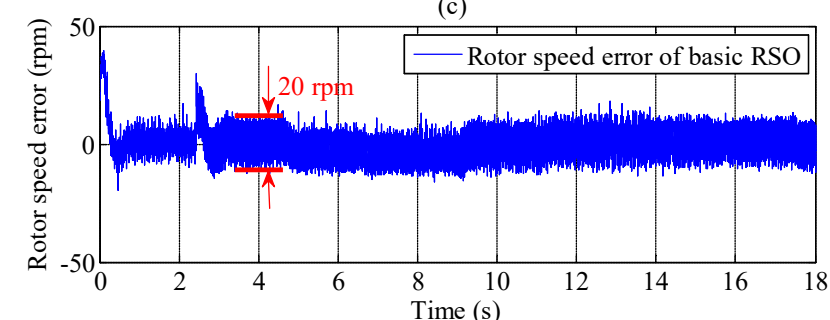

(d)

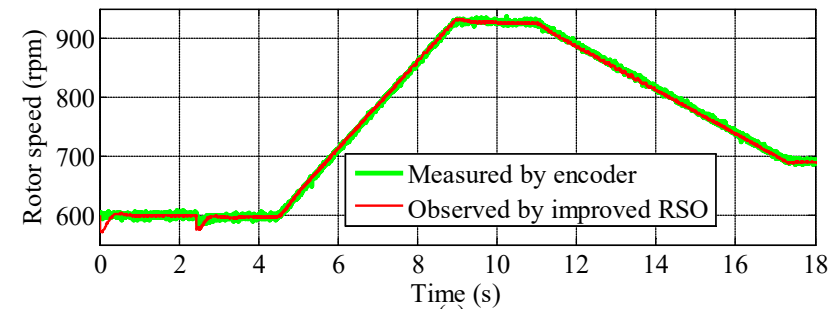

(e)

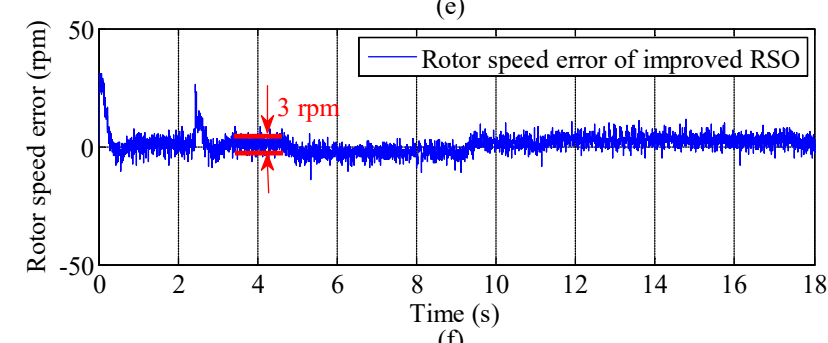

(f)

Fig. 7. Experimental results of the standalone BDFIG supplying a nonlinear load (a diode-rectifier with a $25 \Omega$ resistor at the dc side), where (a) PW voltage $(1 \mathrm{p} . \mathrm{u} .=500 \mathrm{~V})$ and $\mathrm{CW}$ current $(1 \mathrm{p} . \mathrm{u} .=50 \mathrm{~A}),(\mathrm{b})$ Expanded view of (a), (c) Rotor speeds observed by basic RSO and measured by encoder, (d) Error of the rotor speed observed by basic RSO, (e) Rotor speeds observed by improved RSO and measured by encoder, and (f) Error of the rotor speed observed by improved RSO.
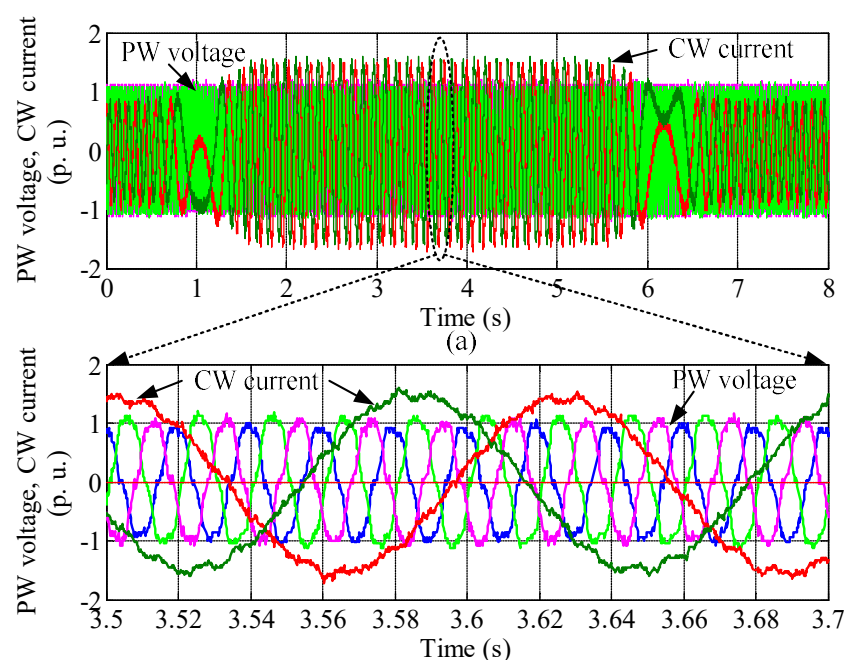

(b)

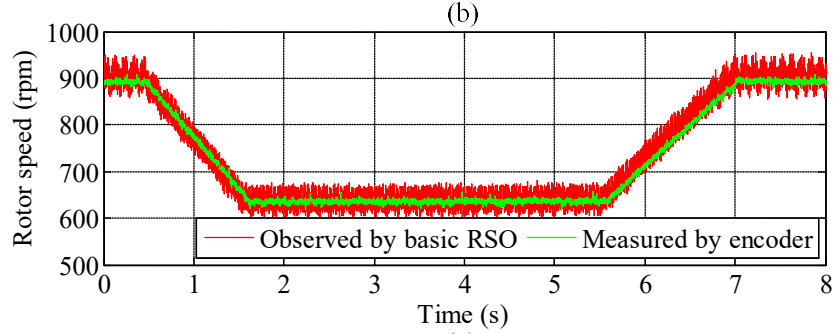

(c)

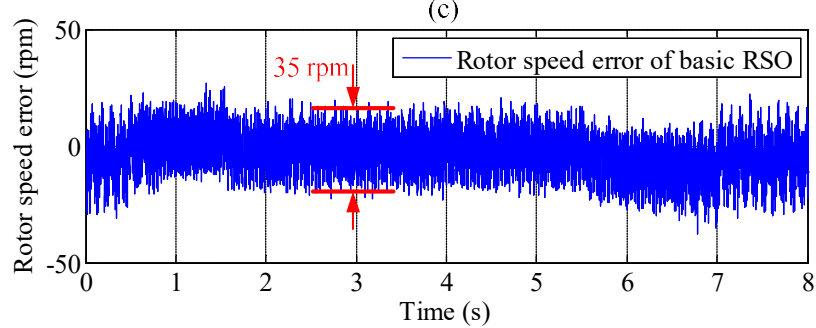

(d)

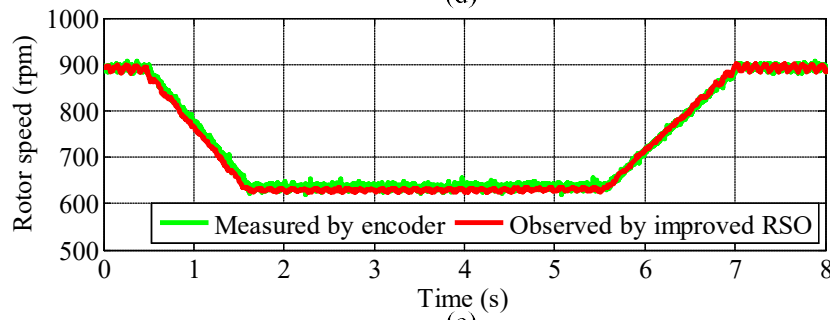

(e)

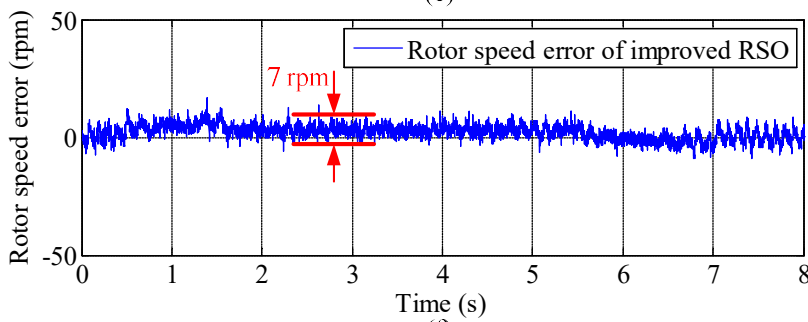

(f)

Fig. 8. Experimental results of the standalone BDFIG supplying a combination load of an unbalanced load and a nonlinear load, where (a) PW voltage $(1$ p. u. $=500 \mathrm{~V})$ and $\mathrm{CW}$ current $(1 \mathrm{p} . \mathrm{u} .=50 \mathrm{~A})$, (b) Expanded view of (a), (c) Rotor speeds observed by basic RSO and measured by encoder, (d) Error of the rotor speed observed by basic RSO, (e) Rotor speeds observed by improved RSO and measured by encoder, and (f) Error of the rotor speed observed by improved RSO. 


\section{IEEE POWER ELECTRONICS REGULAR PAPER}

oscillation has been reduced to around $3 \mathrm{rpm}$ by employing the improved RSO, as shown in Fig. 7(f). Hence, the improved RSO has a better overall performance than the basic one when the standalone BDFIG supplies nonlinear loads.

\section{3) Experiment under Combination Load}

In this experiment, the BDFIG operates at a more severe condition than before. The standalone BDFIG is connected with a combination load of an unbalanced load (a three-phase resistive load with resistances of $6 \Omega, 12 \Omega$ and $12 \Omega$ in three phases) and a nonlinear load (a diode-rectifier with a resistor of $50 \Omega$ at the dc side). Between 0.5 and $1.6 \mathrm{~s}$, the rotor speed drops from 894 to $630 \mathrm{rpm}$ at the rate of $240 \mathrm{rpm}$ per second, and then from 5.5 to $6.97 \mathrm{~s}$, it recovers to $894 \mathrm{rpm}$ at the rate of $180 \mathrm{rpm}$ per second. The rate of the rotor speed change is higher than that in the three experiments above. As shown in Figs. 8(a) and (b), the combination load results that the PW voltage is unbalanced and distorted with the UF of $11.6 \%$ and the THD of $8.6 \%$, and the $\mathrm{CW}$ current is distorted due to the indirect decoupling between $\mathrm{PW}$ and $\mathrm{CW}$ through the rotor. From Figs. 8(c) and (d), the oscillation in the rotor speed observed by the basic RSO reaches $35 \mathrm{rpm}$. At the same operation condition, by employing the improved RSO, the oscillation in the observed rotor speed can be reduced to around $7 \mathrm{rpm}$ as shown in Fig. 8(f), and the observed rotor speed can track the measured one very well as shown in Fig. 8(e).

From the results of all the three typical experiments above, it can be noted that the improved RSO is almost with the same response speed as the basic RSO, although some additional filters (SOGIs and LPFs) have been added to the improved RSO. Hence, it can be concluded that the satisfactory dynamic performance can be offered by the improved RSO.

\section{Steady-state Harmonic Analysis}

Fig. 9 illustrates the expanded views and harmonic spectrums of the rotor speed observed by the basic and improved RSOs under unbalanced loads. The expanded views

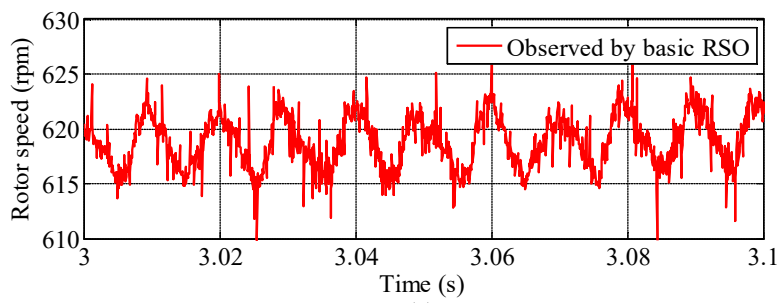

(a)

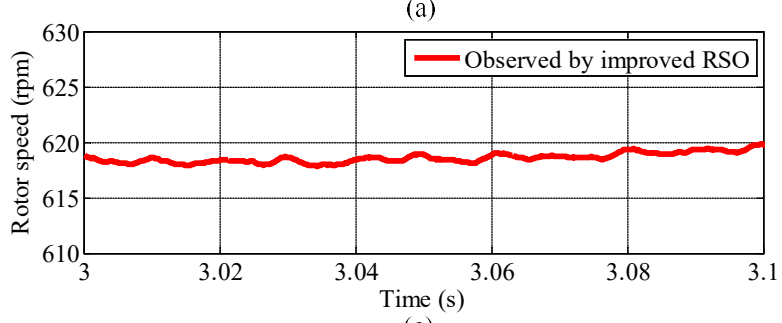

(c) of the rotor speeds shown in Figs. 6(c) and (e) between 3 and $3.1 \mathrm{~s}$ are presented in Figs. 9(a) and (c), respectively. It is obvious that the periodic oscillation appears in the rotor speed observed by the basic RSO, which can be eliminated by the improved RSO. The corresponding harmonics spectrums of the rotor speed are depicted in Figs. 9(b) and (d), respectively. With the basic RSO, the observed rotor speed contains significant harmonics, of which the frequency is twice that of the PW voltage and the amplitude is $0.47 \%$ of the amplitude of the fundamental component (equivalent to $3 \mathrm{rpm}$ ). It is seen that the result is in accordance with the analysis in Part B of Section III. Furthermore, with the improved RSO, the content of the harmonics has been drastically reduced to $0.04 \%$ (equivalent to around $0.25 \mathrm{rpm}$ ).

The expanded views and harmonics spectrums of the rotor speeds observed by the two observers under nonlinear loads are shown in Fig. 10, where the expanded views are based on the rotor speeds as shown in Figs. 7(c) and (e) between 3.7 and 3.8 s. From Figs. 10(a) and (b), it can be seen that the rotor speed observed by the basic RSO contains two main harmonics with frequencies of $6 \omega_{1}$ and $12 \omega_{1}$, which matches the analysis result in Part B of Section III. Employing the improved RSO, the contents of the harmonics with frequencies of $6 \omega_{1}$ and $12 \omega_{1}$ have been reduced from $0.7 \%$ and $0.25 \%$ to $0.07 \%$ and $0.02 \%$, respectively, as shown in Figs. 10(c) and (d).

Fig. 11 presents the expanded views and harmonic spectrums of the rotor speeds observed by the basic and improved observers shown in Figs. 8(c) and (e) between 4.5 and 4.6 s. From Figs. 11(a) and (b), it can be seen that the rotor speed observed by the basic RSO contains two main harmonics with frequencies of $2 \omega_{1}$ and $6 \omega_{1}$, of which the one harmonic with the frequency of $2 \omega_{1}$ is caused by the unbalanced load, and the other one is generated by the nonlinear load, which matches the analysis result in Part B of Section III. Unlike the experiment results under the nonlinear load described above, the harmonic with the frequency of

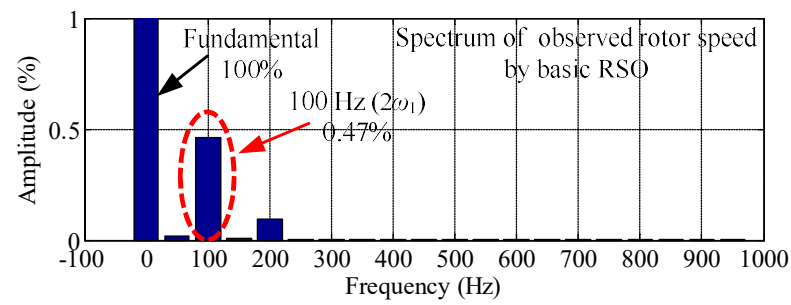

(b)

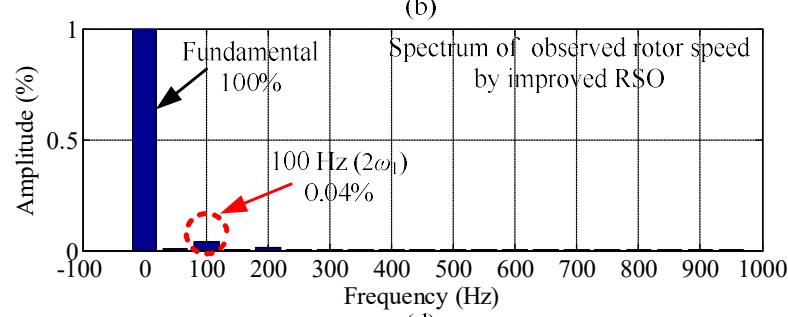

(d)

Fig. 9. Expanded views and harmonic spectrums of rotor speeds observed by basic and improved RSOs under unbalanced loads, where (a) Expanded view of the rotor speed observed by basic RSO, (b) Harmonic spectrum of the rotor speed observed by basic RSO, (c) Expanded view of the rotor speed observed by improved RSO, and (d) Harmonic spectrum of the rotor speed observed by improved RSO. 


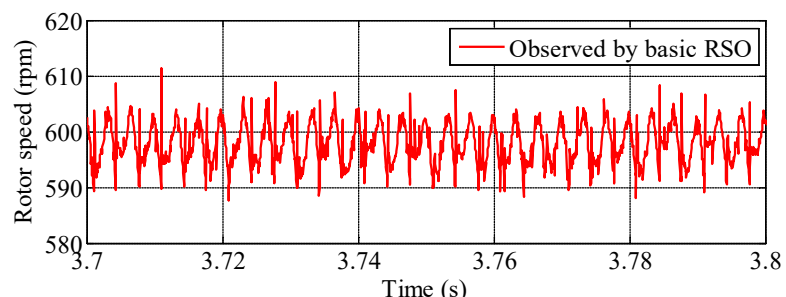

(a)

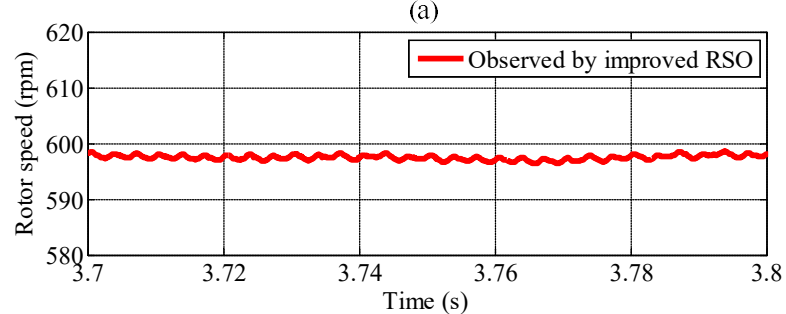

(c)

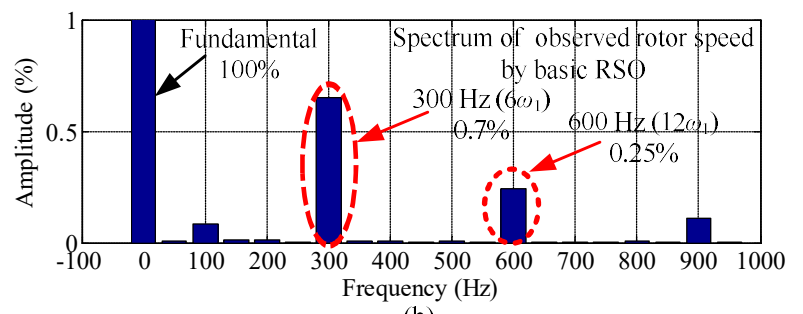

(b)

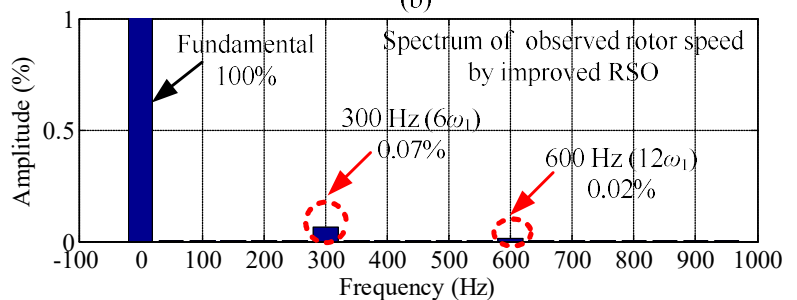

(d)

Fig. 10. Expanded views and harmonic spectrums of rotor speeds observed by basic and improved RSOs under nonlinear loads, where (a) Expanded view of the rotor speed observed by basic RSO, (b) Harmonic spectrum of the rotor speed observed by basic RSO, (c) Expanded view of the rotor speed observed by improved RSO, and (d) Harmonic spectrum of the rotor speed observed by improved RSO.

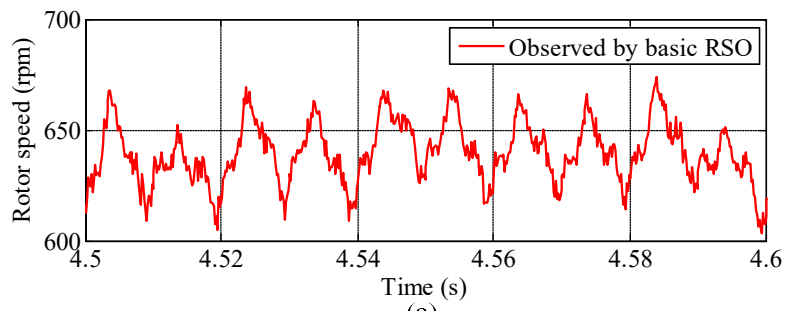

(a)

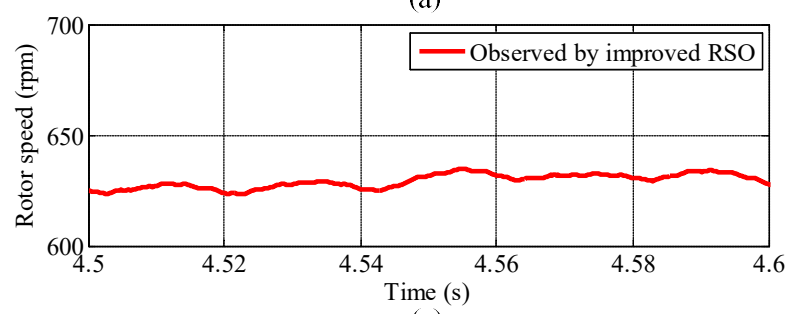

(c)

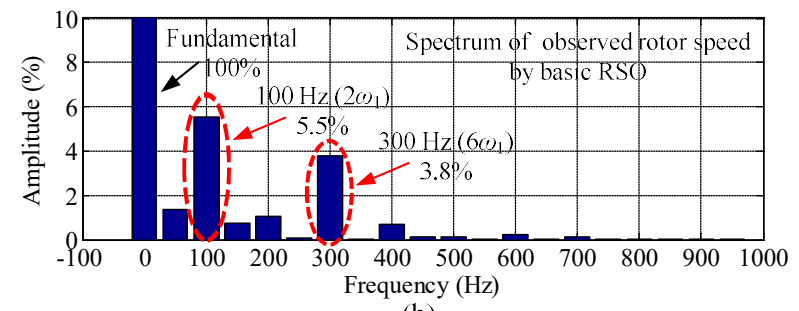

(b)

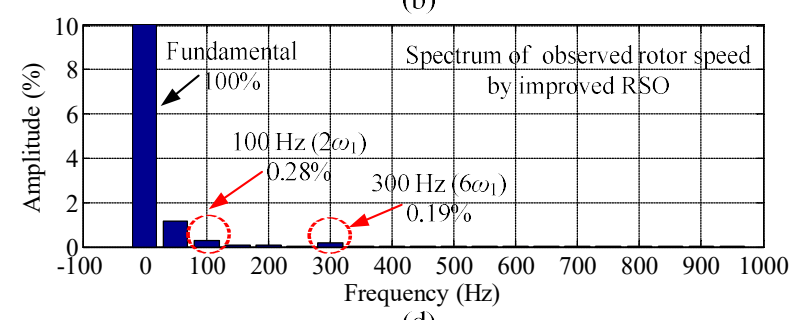

(d)

Fig. 11. Expanded views and harmonic spectrums of rotor speeds observed by basic and improved RSOs under the combination load of the unbalanced and nonlinear loads, where (a) Expanded view of the rotor speed observed by basic RSO, (b) Harmonic spectrum of the rotor speed observed by basic RSO, (c) Expanded view of the rotor speed observed by improved RSO, and (d) Harmonic spectrum of the rotor speed observed by improved RSO.

$12 \omega_{1}$ does not appears in the rotor speed observed by the basic RSO due to few contents of the $7^{\text {th }}$ order PW harmonic voltage generated by the nonlinear load used in this experiment. Fortunately, with the improved RSO, the contents of the harmonics with frequencies of $2 \omega_{1}$ and $6 \omega_{1}$ can be reduced from $5.5 \%$ and $3.8 \%$ to $0.28 \%$ and $0.19 \%$, respectively, as shown in Figs. 11(b) and (d).

\section{SiMULATION RESULTS WITH DFIG}

The proposed improved RSO is independent to machine parameters except the pole pairs, of which the input signals are the voltage of the one winding and the current of the other winding of the electrical machine. Hence, the improved RSO can also be applied to other dual-electrical-port machines, such as the traditional DFIG. The applicability of the improved RSO on DFIG is verified by simulation in this section.

\section{A. Simulation Model and Parameters}

Fig. 12 presents the block diagram of the simulation model for the basic and improved RSOs applied to the standalone DFIG, where $p$ and $\omega_{s l}$ are the pole pairs and slip frequency, the subscripts $s, r$ and $l$ indicate the stator winding, rotor winding and LSC, respectively. For a fair comparison, the MSC control employs a method similar to that used in the BDFIG experiments, i.e. the method developed in [2]. The small difference between the MSC control methods for DFIG and BDFIG is that the DFIG's output voltage (stator voltage) is regulated by the rotor current rather than the stator $\mathrm{CW}$ current, which is determined by the structural differences between the two machines. Besides, the LSC is controlled by utilizing the same method as used in the experiment with 


\section{IEEE POWER ELECTRONICS REGULAR PAPER}

BDFIG, i.e. the method proposed in [22]. Main parameters of the DFIG in this simulation are shown in Table III. And, the control parameters of the two RSOs are the same as that in the experiment with BDFIG (see Table II).

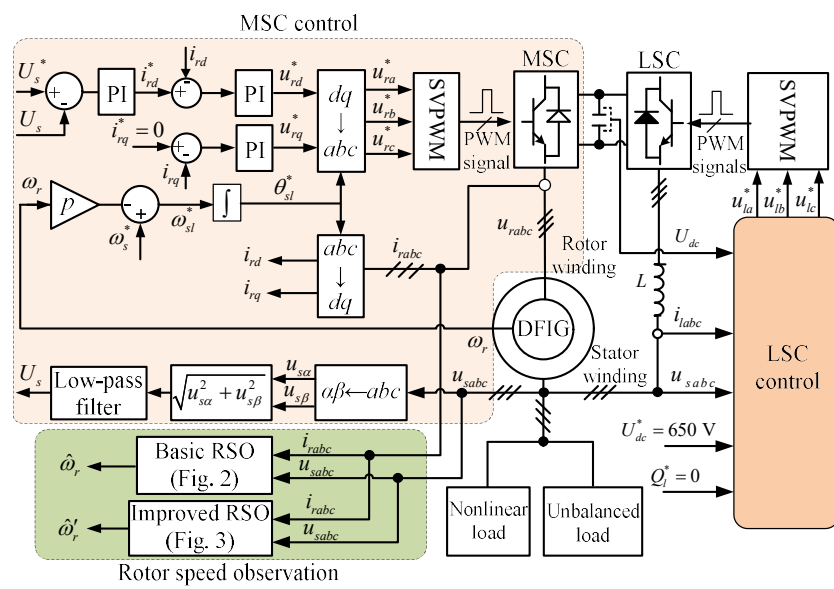

Fig. 12. Block diagram of the simulation model for the basic and improved RSOs applied to the standalone DFIG.

TABLE III

MAIN PARAMETERS OF THE DFIG IN SIMULATION

\begin{tabular}{ll}
\hline \hline Parameter & Value \\
\hline \hline Capacity & $18 \mathrm{kVA}$ \\
Pole pairs & 2 \\
Stator resistance and leakage inductance & $0.5968 \Omega, 0.0003495 \mathrm{H}$ \\
Rotor resistance and leakage inductance & $0.6258 \Omega, 0.005473 \mathrm{H}$ \\
Mutual inductance between stator and rotor & $0.0354 \mathrm{H}$ \\
\hline \hline
\end{tabular}

\section{B. Simulation Results under Unbalanced Load}

The standalone DFIG supplies an unbalanced three-phase resistive load with resistances of $8 \Omega, 12.5 \Omega$ and $12.5 \Omega$ in three phases. The initial rotor speed of the DFIG is $1800 \mathrm{rpm}$. At $4 \mathrm{~s}$, the rotor speed starts to drop at a rate of $1200 \mathrm{rpm}$ per second. As can be seen from Figs. 13(a) and (b), the unbalanced load makes the stator voltage significantly unbalanced with the UF of $9.6 \%$, and the rotor current is distorted due to the magnetic coupling between the stator and rotor. As shown in Fig. 13(c), a great ripple with the peak-topeak value of $200 \mathrm{rpm}$ appears in the rotor speed observed by the basic RSO, which can be significantly reduced by the improved RSO. In addition, the improved RSO has almost the same response speed as the basic RSO, although several additional filters (i.e. SOGIs and LPFs) have been added to the improved RSO. Fig. 13(d) illustrates the expanded view of the rotor speeds shown in Fig. 13(c) between 4.5 and 4.6 s. It is obvious that the periodic oscillation appears in the rotor speed observed by the basic RSO, which can be eliminated by the improved RSO. The harmonic spectrums of the rotor speeds illustrated in Fig. 13(d) are depicted in Fig. 13(e). The rotor speed observed by the basic RSO contains the significant harmonic with the frequency of twice the stator voltage frequency and the content of $5.98 \%$, which is in accordance with the analysis in Part B of Section II. Fortunately, with the improved RSO, the harmonic content can be drastically reduced to $0.43 \%$.
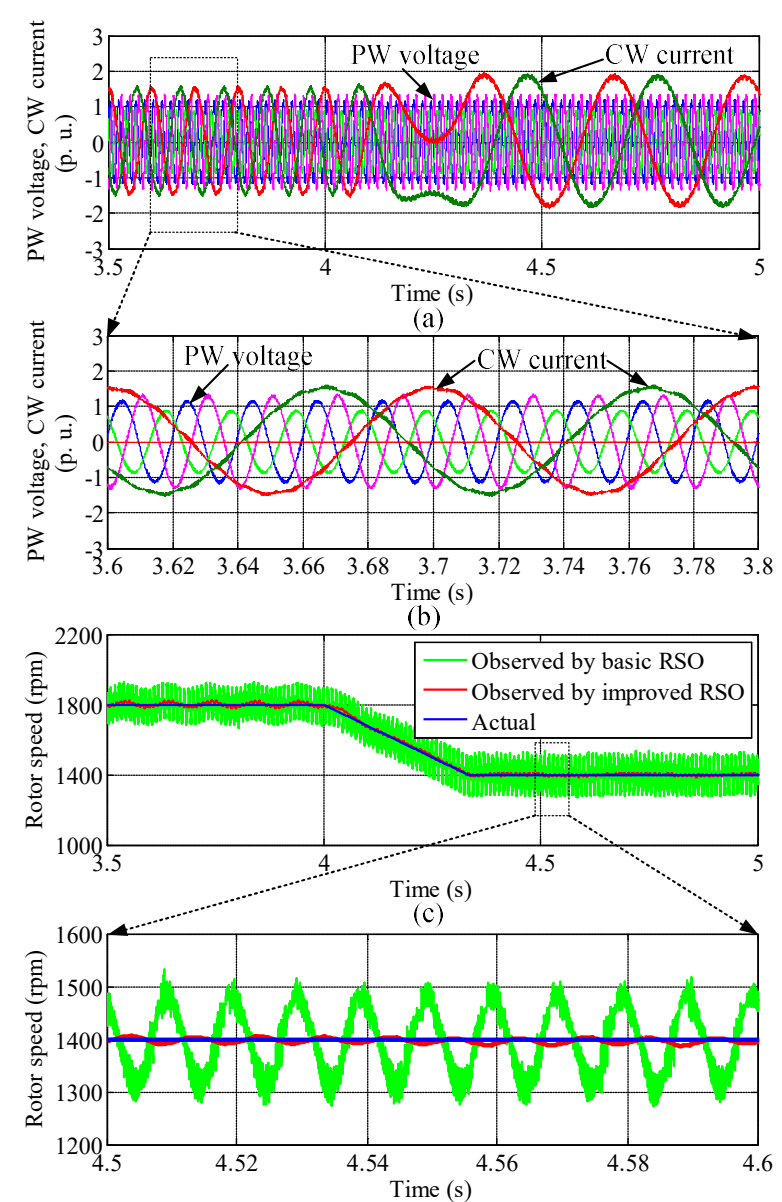

(d)

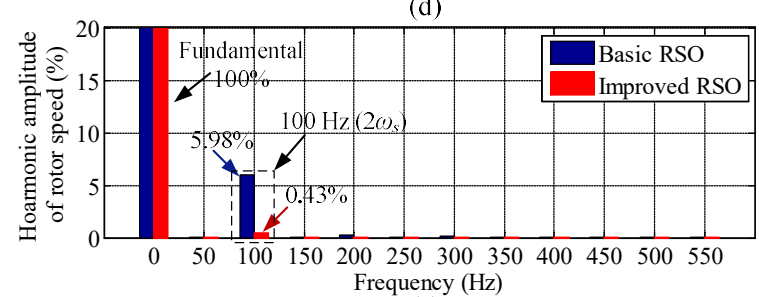

(e)

Fig. 13. Simulation results of the standalone DFIG supplying an unbalanced three-phase resistive load with resistances of $8 \Omega, 12.5 \Omega$ and $12.5 \Omega$ in three phases, where (a) PW phase voltage $(1$ p. u. $=300 \mathrm{~V})$ and $\mathrm{CW}$ phase current $(1 \mathrm{p} . \mathrm{u} .=30 \mathrm{~A}),(\mathrm{b})$ Expanded view of (a), (c) Actual rotor speed and observed ones by basic and improved RSOs, (d) Expanded view of (c), and (e) Harmonic spectrums of the rotor speeds illustrated in (d).

\section{Simulation Results under Nonlinear Load}

In this simulation, the standalone DFIG supplies a balanced load (a three-phase resistive load with resistance of $25 \Omega$ in each phase) and a nonlinear load (a diode-rectifier with a $40 \Omega$ resistor at the dc side) at the same time. The combination load can be regarded as a nonlinear load. The change of the rotor speed is the same as that in the simulation under the unbalanced load. From Figs. 14(a) and (b), it can be seen that the stator voltage is significantly distorted with the THD of 14.3\%. As shown in Figs. 14(c) and (d), the rotor speed observed by the basic RSO contains a periodic oscillation with the great peak-to-peak value of $450 \mathrm{rpm}$. Fortunately, the 


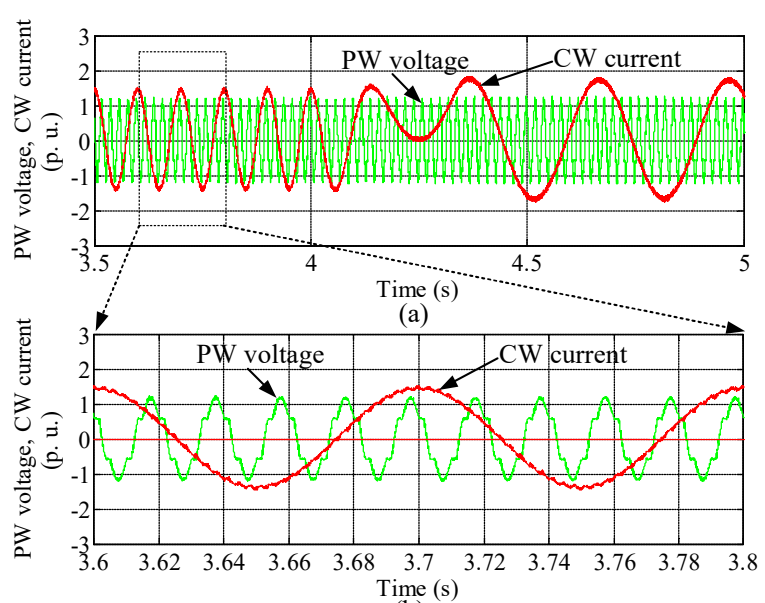

Time $(\mathrm{s})$

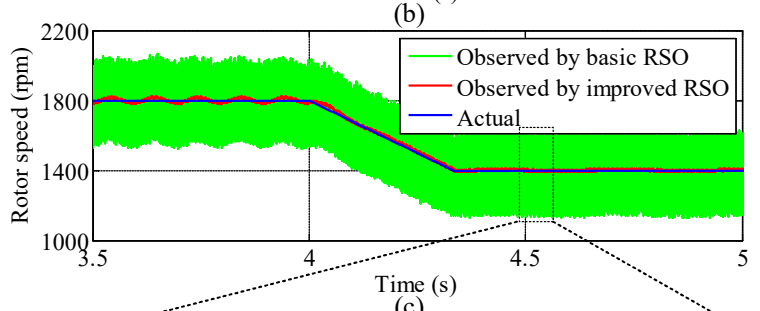

(c)

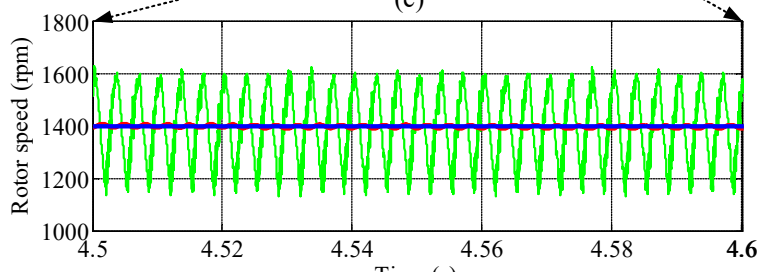

Time $(\mathrm{d})$

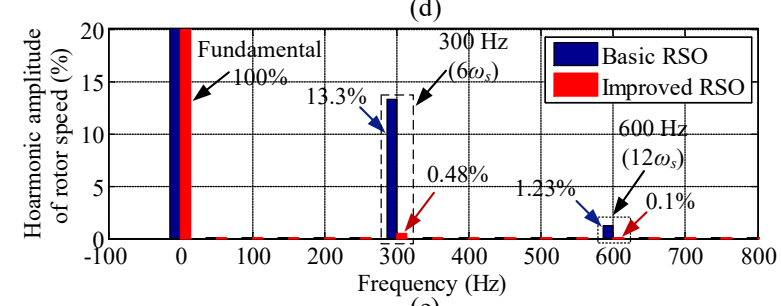

(e)

Fig. 14. Simulation results of the standalone DFIG supplying a combination load of a balanced load (a three-phase resistive load with resistance of $25 \Omega$ in each phase) and a nonlinear load (a diode-rectifier with a $40 \Omega$ resistor at the dc side), where (a) PW phase voltage $(1 \mathrm{p}$. u. $=300 \mathrm{~V})$ and $\mathrm{CW}$ phase current $(1$ p. u. $=30$ A), (b) Expanded view of (a), (c) Actual rotor speed and observed ones by basic and improved RSOs, (d) Expanded view of (c), and (e) Harmonic spectrums of the rotor speeds illustrated in (d).

oscillation in the rotor speed observed by the improved RSO is almost completely eliminated. Moreover, the response speeds of the basic and improved RSOs are almost the same. The comparison of the harmonic spectrums for rotor speeds observed by the two RSOs are presented in Fig. 14(e). It can be seen that the rotor speed observed by the basic RSO contains two main harmonics with frequencies of six times and twelve times the stator voltage frequency, which matches the analysis result in Part B of Section II. With the improved RSO, the two main harmonics can be significantly reduced, of which the contents can be decreased from $13.3 \%$ and $1.23 \%$ to $0.48 \%$ and $0.1 \%$, respectively.
From these simulation results and analysis described above, the improved RSO can achieve satisfactory performance under unbalanced and nonlinear loads.

\section{CONCLUSION}

This paper has proposed an improved RSO used in sensorless control for the standalone BDFIG to improve the reliability and reduce the cost and complexity of the control system. The proposed RSO is based on the PW voltage and $\mathrm{CW}$ current and independent to machine parameters except the pole pairs. In order to eliminate the impact of unbalanced and nonlinear loads on the rotor speed observation, both the SOGI and LPF are added to the RSO to achieve the pre-filtering of PW voltage and $\mathrm{CW}$ current. Through comprehensive parameter design, these additional filters in the improved RSO do not degrade the dynamic performance of the proposed RSO Both dynamic and steady-state performance of the improved RSO applied to the BDFIG are validated by comprehensive experiments under the unbalanced, nonlinear, and combination loads. Furthermore, the application of the improved RSO can be extended to another dual-electrical-port machine (i.e. DFIG), which is verified by simulation results.

\section{APPENDIX}

From (4), it can be derived that

$$
\begin{aligned}
& \left(p_{1}+p_{2}\right) \Delta \theta_{r v} \approx \sin \left[\left(\theta_{1}+\theta_{2}\right)-\left(p_{1}+p_{2}\right) \hat{\theta}_{r v}\right] \\
= & \sin \left(\theta_{1}+\theta_{2}\right) \cos \left(p_{1}+p_{2}\right) \hat{\theta}_{r v}-\cos \left(\theta_{1}+\theta_{2}\right) \sin \left(p_{1}+p_{2}\right) \hat{\theta}_{r v} \\
= & \left(\sin \theta_{1} \cos \theta_{2}+\sin \theta_{2} \cos \theta_{1}\right) \cos \left(p_{1}+p_{2}\right) \hat{\theta}_{r v} \\
& -\left(\cos \theta_{1} \cos \theta_{2}-\sin \theta_{1} \sin \theta_{2}\right) \sin \left(p_{1}+p_{2}\right) \hat{\theta}_{r v}
\end{aligned}
$$

Combining (10) and (33), under unbalanced loads, $\left(p_{1}+p_{2}\right) \Delta \theta_{r v}$ can be expressed as the function of $\theta_{1}^{+1}, \theta_{2}^{+1}, \theta_{1}^{-1}$ and $\theta_{2}^{-1}$, i.e.,

$$
\begin{aligned}
\left(p_{1}+p_{2}\right) \Delta \theta_{r v} \approx & K_{1} K_{3} \sin \left[\left(\theta_{1}^{+1}+\theta_{2}^{+1}\right)-\left(p_{1}+p_{2}\right) \hat{\theta}_{r v}\right] \\
& +K_{2} K_{3} \sin \left[\left(\theta_{1}^{-1}+\theta_{2}^{+1}\right)-\left(p_{1}+p_{2}\right) \hat{\theta}_{r v}\right] \\
& +K_{1} K_{4} \sin \left[\left(\theta_{1}^{+1}+\theta_{2}^{-1}\right)-\left(p_{1}+p_{2}\right) \hat{\theta}_{r v}\right] \\
& +K_{2} K_{4} \sin \left[\left(\theta_{1}^{-1}+\theta_{2}^{-1}\right)-\left(p_{1}+p_{2}\right) \hat{\theta}_{r v}\right]
\end{aligned}
$$

And then, substituting (8) and (9) to (34), Eq. (11) can be obtained. Similarly, substituting (16) to (33), $\left(p_{1}+p_{2}\right) \Delta \theta_{r v}$ can be rewritten as the function of $\theta_{1}^{+1}, \theta_{2}^{+1}, \theta_{1}^{-5}, \theta_{2}^{-5}, \theta_{1}^{+7}$ and $\theta_{2}^{+7}$ under nonlinear loads, i.e.,

$$
\begin{aligned}
\left(p_{1}+p_{2}\right) \Delta \theta_{r v} \approx & K_{1} K_{4} \sin \left[\left(\theta_{1}^{+1}+\theta_{2}^{+1}\right)-\left(p_{1}+p_{2}\right) \hat{\theta}_{r v}\right] \\
& +K_{1} K_{5} \sin \left[\left(\theta_{1}^{+1}+\theta_{2}^{-5}\right)-\left(p_{1}+p_{2}\right) \hat{\theta}_{r v}\right] \\
& +K_{1} K_{6} \sin \left[\left(\theta_{1}^{+1}+\theta_{2}^{+7}\right)-\left(p_{1}+p_{2}\right) \hat{\theta}_{r v}\right] \\
& +K_{2} K_{4} \sin \left[\left(\theta_{1}^{-5}+\theta_{2}^{+1}\right)-\left(p_{1}+p_{2}\right) \hat{\theta}_{r v}\right] \\
& +K_{2} K_{5} \sin \left[\left(\theta_{1}^{-5}+\theta_{2}^{-5}\right)-\left(p_{1}+p_{2}\right) \hat{\theta}_{r v}\right] \\
& +K_{2} K_{6} \sin \left[\left(\theta_{1}^{-5}+\theta_{2}^{+7}\right)-\left(p_{1}+p_{2}\right) \hat{\theta}_{r v}\right] \\
& +K_{3} K_{4} \sin \left[\left(\theta_{1}^{+7}+\theta_{2}^{+1}\right)-\left(p_{1}+p_{2}\right) \hat{\theta}_{r v}\right] \\
& +K_{3} K_{5} \sin \left[\left(\theta_{1}^{+7}+\theta_{2}^{-5}\right)-\left(p_{1}+p_{2}\right) \hat{\theta}_{r v}\right] \\
& +K_{3} K_{6} \sin \left[\left(\theta_{1}^{+7}+\theta_{2}^{+7}\right)-\left(p_{1}+p_{2}\right) \hat{\theta}_{r v}\right]
\end{aligned}
$$




\section{IEEE POWER ELECTRONICS REGULAR PAPER}

Finally, Eq. (17) can be obtained by substituting (8), (14) and (15) to (35).

\section{REFERENCES}

[1] R. A. McMahon, P. C. Roberts, X. Wang, and P. J. Tavner, "Performance of BDFM as generator and motor," IEE Proc.-Elect. Power Appl., vol. 153, no. 2, pp.289-299, Mar. 2006.

[2] Y. Liu, W. Ai, B. Chen, K. Chen, and G. Luo, "Control Design of the Brushless Doubly-Fed Machine for Standalone VSCF Ship Shaft Generator Systems," J. Power Electron., vol. 16, no. 1, pp.259-267, Jan. 2016.

[3] S. Shao, E. Abdi, F. Barati, and R. McMahon, "Stator-flux-oriented vector control for brushless doubly-fed induction generator," IEEE Trans. Ind. Electron., vol. 56, no. 10, pp. 4220-4228, Oct. 2009.

[4] S. Shao, T. Long, E. Abdi and R. A. McMahon, "Dynamic control of the brushless doubly fed induction generator under unbalanced operation," IEEE Trans. Ind. Electron., vol. 60, no. 6, pp.2465-2476, June 2013.

[5] Y. Liu, W. Xu, G. Zhi, J. Zhang, "Performance analysis of the standalone brushless doubly-fed induction generator by using a new Ttype steady-state model," J. Power Electron., vol. 17, no. 4, pp. 10271036, 2017.

[6] Y. Liu, W. Ai, B. Chen, and K. Chen, "Control design and experimental verification of the brushless doubly-fed machine for standalone power generation applications," IET Elect. Power Appl., vol. 10, no. 1, pp.25$35,2016$.

[7] Y. Liu, W. Xu, K. Yu, and F. Blaabjerg, "A new vector control of brushless doubly-fed induction generator with transient current compensation for stand-alone power generation applications," in Proc. IEEE Appl. Power Electron. Conf. Expo. (APEC), 2018, pp. 1392-1398.

[8] L. Sun, Y. Chen, J. Su, D. Zhang, L. Peng, Y. Kang, "Decoupling network design for inner current loops of stand-alone brushless doubly fed induction generation power system," IEEE Trans. Power Electron., vol. 33 , no. 2 , pp. 957-963, 2018.

[9] S. Shao, E. Abdi, and R. McMahon, "Low-cost variable speed drive based on a brushless doubly-fedmotor and a fractional unidirectional converter," IEEE Trans. Ind. Electron., vol. 59, no. 1, pp. 317-325, Jan. 2012.

[10] A. Zhang, X. Wang, W. Jia, and Y. Ma, "Indirect stator-quantities control for the brushless doubly fed induction machine," IEEE Trans. Power Electron., vol. 29, no. 3, pp. 1392-1401, Mar. 2014.

[11] I. Sarasola, J. Poza, M. A. Rodriguez, and G. Abad, "Direct torque control design and experimental evaluation for the brushless doubly fed machine," Energy Convers. Manage., vol. 52, no. 2, pp. 1226-1234, Feb. 2011.

[12] F. Barati, R. McMahon, S. Shao, E. Abdi, and H. Oraee, "Generalized vector control for brushless doubly fed machines with nested-loop rotor," IEEE Trans. Ind. Electron., vol. 60, no. 6, pp. 2477-2485, Jun. 2013.

[13] T. Long, S. Shao, P. Malliband, E. Abdi, and R. A. McMahon, "Crowbarless fault ride-through of the brushless doubly fed induction generator in a wind turbine under symmetrical voltage dips," IEEE Trans. Ind. Electron., vol. 60, no. 7, pp. 2833-2840, Jul. 2013.

[14] M. G. Jovanović, D. G. Dorrell, "Sensorless control of brushless doublyfed reluctance machines using an angular velocity observer," in Proc. Int. Conf. Power Electron. Drive Syst. (PEDS), 2007, pp.717-724.

[15] S. Ademi, M. G. Jovanović, H. Chaal, W. Cao, "A New sensorless speed control scheme for doubly fed reluctance generators," IEEE Trans. Energy Convers., vol. 31, no. 3, pp.993-1001, Mar. 2016.

[16] V. T. Phan and H. H. Lee, "Performance enhancement of stand-alone DFIG systems with control of rotor and load side converters using resonant controllers," IEEE Trans. Ind. Appl., vol. 48, no. 1, pp. 199-210, Jan. 2012

[17] M. Cheng, Y. Jiang, P. Han, and Q. Wang, "Unbalanced and low-order harmonic voltage mitigation of stand-alone dual-stator brushless doubly fed induction wind generator," IEEE Trans. Ind. Electron., vol. 65, no. 11, pp. 9135-9146, Nov. 2018.

[18] W. Xu, K. Yu, and Y. Liu, "Improved coordinated control of standalone brushless doubly-fed induction generator supplying nonlinear loads," IEEE Trans. Ind. Electron., in press.

[19] Y. Liu, W. Xu, T. Long, and F. Blaabjerg, "A new rotor speed observer for stand-alone brushless doubly-fed induction generators," in Proc. IEEE Energy Convers. Cong. Expo. (ECCE), 2017, pp. 5086-5092.

[20] Y. Liu, W. Xu, J. Zhu, and F. Blaabjerg, "Sensorless control of standalone brushless doubly-fed induction generator feeding unbalanced loads in ship shaft power generation system," IEEE Trans. Ind. Electron. vol. 66, no. 1, pp. 739-749, Jan. 2019..

[21] S.-K. Chung, "Phase-locked loop for grid-connected three-phase power conversion systems," IEE Proc.-Elect. Power Appl., vol. 147, no. 3, pp.213-219, May 2000.

[22] R. Teodorescu and F. Blaabjerg, "Flexible control of small wind turbines with grid failure detection operating in standalone and grid-connected mode," IEEE Trans. Power Electron., vol. 19, no. 5, pp. 1323-1332, Sep. 2004.

[23] P. Rodriguez, R. Teodorescu, I. Candela, A. V. Timbus, M. Liserre, and F. Blaabjerg, "New positive-sequence voltage detector for grid synchronization of power converters under faulty grid conditions," in Proc. 37th IEEE Power Electron. Specialists Conf., 2016, pp. 1-7.

[24] G. Ellis, Control System Design Guide, 3rd ed. USA: Elsevier Academic Press, Feb. 2004.

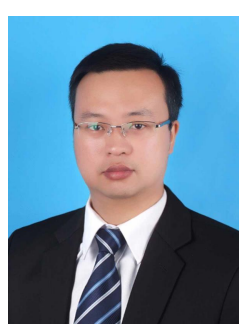

Yi Liu (M'14) received the B.E. and M.E. degrees in automation and control engineering from the Wuhan University of Science and Technology, Wuhan, China, in 2004 and 2007, respectively, and the Ph.D. degree in mechatronic engineering from the Huazhong University of Science and Technology, Wuhan, China, in 2016.

From 2007 to 2011, he was a Lecturer with the City College, Wuhan University of Science and Technology. From March 2016 to June 2016, he was a Senior R\&D Engineer at the Fourth Academy of China Aerospace Science and Industry Group, Wuhan. In June 2016, he joined the School of Mechanical and Electrical Engineering, Huanggang Normal University. Since July 2016, he has been a Postdoctoral Research Fellow with the State Key Laboratory of Advanced Electromagnetic Engineering and Technology, School of Electrical and Electronic Engineering, Huazhong University of Science and Technology. His current research interests include ac electrical machine control and inverter systems.

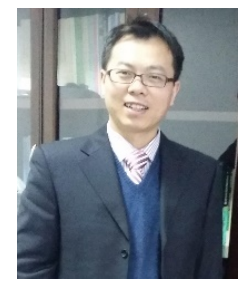

Wei Xu (M'09-SM'13) received the double B.E. and M.E. degrees from Tianjin University, Tianjin, China, in 2002 and 2005, and the Ph.D. from the Institute of Electrical Engineering, Chinese Academy of Sciences, in 2008, respectively, all in electrical engineering.

From 2008 to 2012, he held several academic positions in both Australian and Japanese universities and companies. Since 2013, he has been full professor with the State Key Laboratory of Advanced Electromagnetic Engineering and Technology, Huazhong University of Science and Technology, China. His research topics mainly cover design and control of linear/rotary machines.

Dr. Xu is a Fellow of the Institute of Engineering and Technology (IET). He has served as Associate Editor for several Journals, such as IEEE Transactions on Industrial Electronics, IEEE Journal of Emerging and Selected Topics in Power Electronics, IEEE Transactions on Vehicular Technology, etc.

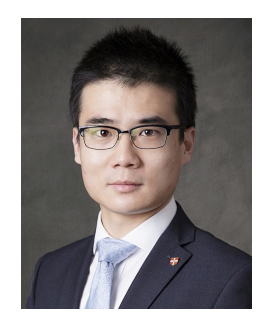

Teng Long (M'13) received the B.Eng. degree from the Huazhong University of Science and Technology, China, the first class B.Eng. (Hons.) degree from the University of Birmingham, UK in 2009, and the Ph.D. degree from the University of Cambridge, UK in 2013. Until 2016, he was a Power Electronics Engineer with the General Electric (GE) Power Conversion business in Rugby, UK. He is currently a Lecturer with the University of Cambridge. His research interests include power electronics, electrical machines, and machine drives. Dr Long is a Chartered Engineer (CEng) registered with the Engineering Council in the UK. 


\section{IEEE POWER ELECTRONICS REGULAR PAPER}

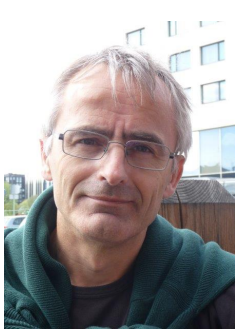

Frede Blaabjerg (S'86-M'88-SM'97-F'03) was with ABB-Scandia, Randers, Denmark, from 1987 to 1988. From 1988 to 1992 , he got the PhD degree in Electrical Engineering at Aalborg University in 1995. He became an Assistant Professor in 1992, an Associate Professor in 1996, and a Full Professor of power electronics and drives in 1998. From 2017 he became a Villum Investigator. He is honoris causa at University Politehnica Timisoara (UPT), Romania and Tallinn Technical University (TTU) in Estonia.

His current research interests include power electronics and its applications such as in wind turbines, PV systems, reliability, harmonics and adjustable speed drives. He has published more than 600 journal papers in the fields of power electronics and its applications. He is the co-author of four monographs and editor of ten books in power electronics and its applications.

$\mathrm{He}$ has received 30 IEEE Prize Paper Awards, the IEEE PELS Distinguished Service Award in 2009, the EPE-PEMC Council Award in 2010, the IEEE William E. Newell Power Electronics Award 2014 and the Villum Kann Rasmussen Research Award 2014. He was the Editor-in-Chief of the IEEE TRANSACTIONS ON POWER ELECTRONICS from 2006 to 2012. He has been Distinguished Lecturer for the IEEE Power Electronics Society from 2005 to 2007 and for the IEEE Industry Applications Society from 2010 to 2011 as well as 2017 to 2018. In 2019-2020 he serves President of IEEE Power Electronics Society. He is Vice-President of the Danish Academy of Technical Sciences too.

He is nominated in 2014-2018 by Thomson Reuters to be between the most 250 cited researchers in Engineering in the world. 